CAHIER DE RECHERCHE \#1506E

WORKING PAPER \#1506E

Département de science économique

Department of Economics

Faculté des sciences sociales

Faculty of Social Sciences

Université d'Ottawa

University of Ottawa

\title{
Endogenous Efficiency Gains from Mergers with and without Product Differentiation*
}

\author{
Gamal Atallah ${ }^{\dagger}$
}

September 2015

\footnotetext{
* I would like to thank Mihkel Tombak, seminar participants at the University of Ottawa, participants to the Meetings of La Société canadienne de science économique and the Canadian Economics Association for their useful feedback and suggestions.

${ }^{\dagger}$ Department of Economics, University of Ottawa, 120 University Private, Ottawa, Ontario, Canada, K1N 6N5; email: gatallah@uottawa.ca.
} 


\begin{abstract}
This paper analyzes endogenous efficiency gains from mergers. It considers oligopolistic homogeneous good markets and duopolistic and triopolistic markets under product differentiation (quantity and price competition). In a two-stage game, firms invest in cost-reducing innovation (with and without mergers) and then compete in output/prices. It is found that in homogeneous good markets, all possible mergers generate efficiency gains, and that these are most significant when spillovers are very low or very high. Efficiency gains increase with the number of insiders and generally decrease with the number of outsiders. With product differentiation, under quantity competition, and under price competition with outsiders to the merger, the merger generates efficiency gains when $R \& D$ spillovers and/or product differentiation are sufficiently high. Under price competition with a merger to monopoly, the merger induces efficiency gains except when spillovers are very low. With product differentiation, efficiency gains increase with $R \& D$ spillovers, but may increase or decrease with the level of product differentiation. Innovation incentives and the likelihood of efficiency gains are compared between quantity and price competition. The implications of the results for the relationship between competition and innovation outputs and for merger policy are discussed.
\end{abstract}

Key words: Mergers, Efficiency gains, Cost reduction, $R \& D$, Process $R \& D, R \& D$ spillovers, Antitrust, Competition policy

JEL Classification: D43, L13, L40, O30

\title{
Résumé
}

Cette étude analyse les gains d'efficacité endogènes résultant des fusions. Elle considère des marchés oligopolistiques de produits homogènes ainsi que des marchés de duopole et de triopole avec produits différentiés (concurrence en quantités et en prix). Dans un jeu à deux étapes, les firmes investissent dans la réduction des coûts (avec et sans fusion) et ensuite se concurrencent en quantités/prix. Il est démontré qu'avec un produit homogène, toutes les fusions possibles génèrent des gains d'efficacité, et que ces gains sont plus importants lorsque les externalités de recherche sont très faibles ou très élevées. Les gains d'efficacité augmentent avec le nombre de firmes fusionnées et, généralement, diminuent avec le nombre de firmes non-fusionnées. Lorsque les produits sont différentiés, avec concurrence en quantités, et avec concurrence en prix mais sans atteindre une situation de monopole, la fusion génère des gains d'efficacité lorsque les externalités de recherche et/ou la différentiation des produits sont suffisamment élevées. Avec concurrence en prix et une fusion menant à un monopole, la fusion génère des gains d'efficacité, sauf lorsque les externalités de recherche sont très faibles. Avec des produits différentiés, les gains d'efficacité augmentent avec les externalités de recherche, mais peuvent augmenter ou diminuer avec le niveau de différentiation des produits. Les incitations à l'innovation et la vraisemblance d'obtenir des gains d'efficacité sont comparées entre les régimes de concurrence en quantités et de concurrence en prix. Les implications des résultats pour la relation entre la concurrence et l'innovation, et pour la politique en matière de fusions, sont discutées.

Mots clés : Fusions, Gains d'efficacité, Réduction des coûts, $R \& D, R \& D$ en matière de procédés, Externalités de recherche, Antitrust, Politique de la concurrence

Classification JEL : D43, L13, L40, O30 


\section{Introduction}

Efficiency gains $(E G)^{1}$ are key to merger analysis. They can be the result of a number of factors such as economies of scale, economies of scope, rationalization, employment reduction, innovation, reductions in transaction costs (Coates, 2005), reallocation of intangible assets (Motis et al., 2006), etc. On the one hand, antitrust authorities accept an efficiency defence as a countervailing factor to be measured against market power effects; furthermore, a reduction in innovation is considered as an anticompetitive effect of mergers (Horizontal Merger Guidelines, 2010; Slaughter and May, 2012). On the other hand, EG are not a substitute for competition. As Monti (2006:ix) notes: "Without sufficient competitive pressure, there can be no assurance either that the merged company will make the efforts needed to improve efficiency or that it will pass on any benefits from efficiency gains to its customers." Efficiency defense is most relevant when it is based on documented merger-specific efficiencies (that is, just observing that costs go down following a merger is not proof of EG; the question must be: would costs have gone down more or less without the merger?) which are likely to be passed on to consumers (see, for example, Yde and Vita (1996), who question the pass-on requirement). A similar approach, with some variants, is followed in Canada, the European Union (since 2004), Australia, and New Zealand (Werden et al., 2005). In some cases, claims of EG may even increase the likelihood that a merger is challenged: ambitious claims of EG may aim at compensating for serious anticompetitive effects, making the authorities particularly sceptical about such assertions (Avalos and De Hoyos, 2008).

This paper analyzes endogenous efficiency effects of mergers. Ex ante symmetric firms compete in two stages, first choosing cost-reducing innovation (with and without a merger), then output or price. R\&D investments and unit costs are compared between the merger and no merger outcomes. EG obtain if the marginal cost of the merged firms is lower than their marginal cost without the merger.

We start with a $k$-firm homogeneous good Cournot model. It is shown that in this setting all possible mergers induce EG. This is because the effect of the increase in R\&D by the merged entity and by outsiders (due to the increase in concentration) dominates the loss of the R\&D of

\footnotetext{
${ }^{1}$ In this footnote we collect all the abbreviations used in the paper: efficiency gains (EG), efficiency losses (EL), quantity competition (QC), price competition (PC), product differentiation (PD).
} 
the firms which have "disappeared" following the merger. Moreover, EG are most important when spillovers are very low or very high. EG increase with the number of insiders and (almost always) decrease with the number of outsiders.

We then consider product differentiation (PD) in a duopoly and a triopoly, and analyze both quantity competition (QC) and price competition (PC). It is found that under QC (as well under PC when there is an outsider), EG are most likely when spillovers and/or PD are sufficiently high. This is because with high spillovers, R\&D investments without the merger are depressed, due to the significant leakage to the competitor, whereas this externality is internalized with the merger. Furthermore, with high PD, competition is softened, firms invest less in $R \& D$ when they are independent, and mergers increase $R \& D$ and reduce costs.

Under PC with no outsider, EG result from the merger, except when spillovers are very low. Furthermore, under PD: 1) the presence of an outsider reduces the likelihood of EG; 2) for merger to monopoly, under QC (PC), higher initial concentration reduces (increases) the likelihood of EG; 3) merger to monopoly is more likely to induce EG under PC than under QC, while the opposite is true for partial mergers; and 4) EG increase with R\&D spillovers, but may increase or decrease with PD. The results point to an important difference between homogeneous good markets and markets with differentiated products: while with homogenous products all mergers generate EG, with PD mergers tend to generate EG only when spillovers and/or PD are sufficiently high.

Our paper expands on a large literature that examines the links between mergers and innovation. A brief overview of some of the earlier research will demonstrate the ways in which this study contributes to the field. Williamson (1968) uses social welfare to analyze the trade-off between internal efficiencies and the enhanced market power resulting from the merger. Salant et al. (1983) note that mergers with EG (through economies of scale) may still be unprofitable, and may also increase social welfare through the benefits they provide upon outsiders.

Tombak (2002) studies mergers between competitors endowed with different costs, where the (superior) technology of the owner can be transferred to an acquired firm. He finds that in the equilibrium sequence of mergers, the largest firm acquires the next largest firm. The initial mergers are welfare-enhancing, but eventually the mergers can decrease welfare. While 
Tombak's paper considers sequential mergers between asymmetric firms, it does not incorporate R\&D or innovation per se, which is addressed in this study.

Cabolis et al. (2005) study profitability and welfare effects of a merger of two firms in a Cournot triopoly with cost-reducing R\&D. They focus on homogeneous products and distinguish between merger and acquisition; they conclude that a merger will arise in equilibrium if the cost of doing R\&D is low enough. They extend the base model by incorporating spillovers and find that the merger is profitable when spillovers are low enough. They also consider PD as an extension (but with no spillovers), and find that merger is an equilibrium when the cost of R\&D is low enough and PD is high enough. Our paper goes further than Cabolis et al. (2005) in a number of areas. In the homogeneous good case, we consider a market composed of any number of firms, and mergers between any subset of firms. Under PD, we add R\&D spillovers to the model, as well as PC, and consider duopoly and triopoly. And for all models, our focus is EG, not profitability or social welfare. In particular, whereas the results of Cabolis et al. (2005) show that profitability depends on the cost of $R \& D$ and spillovers, here we show these two variables have no effect on the sign of EG (in the homogeneous good case), although they do affect their magnitudes. One major difference between our work and the work of Cabolis et al. (2005) is that they consider R\&D investments prior to the merger, and how they affect the profitability of integration. Whereas we compare costs if the merger does not occur (given the hypothetical R\&D investments firms would make without merger) with costs if the merger occurs (given the hypothetical R\&D investments firms would make under merger). EG in our model (when they exist) are merger-specific: they obtain only if the merger occurs. ${ }^{2}$

Atallah (2005) studies mergers between an arbitrary number of firms in oligopoly, allowing for R\&D spillovers, but he focuses on merger profitability, and does not consider PD.

In a tournament model involving $n$ firms, Jost and van der Velden (2006) study synergies from mergers through returns to scale in $\mathrm{R} \& \mathrm{D}$. They show that mergers are profitable and reduce R\&D costs. They also consider the effect of spillovers, which raise the threshold of synergies for merger profitability. In their model, synergies are in terms of R\&D costs, not production costs.

Davidson and Ferret (2007) study mergers in the presence of R\&D under QC and PC;

${ }^{2}$ Cabolis et al. (2008) use a similar framework to Cabolis et al. (2005) and, among other things, consider the effect of the share of each merged firm in post-merger profits on the incentives to merge. 
they consider the merger of two firms in a $\mathrm{N}$-firm industry. They find that for sufficiently high R\&D complementarities, the merger benefits insiders and increases their size, and harms outsiders; these results hold under both PC and QC. They allow for spillovers between the merged firms, but there are no spillovers between the latter and outsiders (and there are no spillovers at all prior to the merger). Our paper goes beyond their work by allowing for $R \& D$ spillovers, analyzing EG explicitly and considering mergers of more than two firms.

Banal-Estañol et al. (2008) show that internal conflicts within the merged firm may eliminate EG and even generate efficiency losses (EL). Kleer (2012) analyzes mergers and innovation, allowing for different cases (competition between divisions, quantity leadership of the merged entity, etc.). However, his model does not address PD or R\&D spillovers, and he considers only a merger of two firms in a triopoly.

Matsushima et al. (2013) study mergers (both pairwise and of an arbitrary number of firms) in a homogeneous good oligopoly with no spillovers. They focus on firm heterogeneity: some firms are efficient, some are inefficient. They find that the presence of R\&D increases the likelihood of the private and social profitability of mergers; they also show that mergers involving (more) efficient firms are more privately and socially valuable. They find discrepancies between equilibrium mergers and socially desirable ones. Our paper extends their work since it incorporates R\&D spillovers, explicitly analyzes EG, and considers PD (which they do not).

de Bettignies and Ross (2014) analyze EG in the presence of agency costs. In their Cournot duopoly model, risk-neutral agents make cost-reducing investments. They show that when investments are verifiable mergers reduce costs, but when they are not verifiable mergers can induce EL when the investment cost is sufficiently convex. Their results complement our analysis; however, they restrict their analysis to a duopoly, and do not consider PD or spillovers.

Jovanovic (2014) studies synergies from mergers in a principal-agent framework. However, he studies only mergers involving two firms, and considers neither PD nor R\&D spillovers. Cunha and Vasconcelos (2015) study the effect of EG on mergers in a Stackelberg market; they show that in this setting EG can make mergers profitable as well as welfare enhancing.

A branch of the literature has considered the effect of uncertainty about EG. In a 
duopolistic model of cost-reducing R\&D with a homogeneous product, Stenbacka (1991) shows that when a firm has private information about its costs it prefers not to reveal this information before the merger, and $R \& D$ investments and expected consumer surplus are higher under incomplete information. Le Pape and Zhao (2012) study the profitability of mergers in a Stackelberg market when EG (or EL) are uncertain. Cunha et al. (2014) consider the impact of uncertainty in EG on merger outcomes and approval; they find that uncertainty benefits firms and consumers, and may, for high levels of uncertainty, increase the likelihood of firms proposing a merger and the antitrust authority approving it.

One central feature of the current paper is its focus on EG, rather than merger profitability. Economists tend to restrict the theoretical analysis of mergers to (theoretically) profitable mergers: if the merger is deemed unprofitable ex ante, firms will not attempt to implement it, and there is no need for antitrust theory to study the welfare consequences of such a merger. However, this argument overlooks the fact that a substantial proportion of real-world mergers turn out to be unprofitable, an issue which is persistent in time and place. An early study by Hogarty (1970) reports that a substantial proportion of mergers have a neutral or negative effect on profitability. Amel et al. (2004) study the profitability of mergers and acquisitions in the financial industry, and find that consolidation in this sector is profitable up to a small size, but "there is little evidence that mergers yield economies of scope or gains in managerial efficiency" (p. 2493). Reviewing a number of empirical studies on merger profitability, Budzinski and Kretschmer (2007) report that unprofitable mergers constitute between $25 \%$ and $50 \%$ of mergers. Ferrer (2011) also reports negative return on equity, using data from the Philippines Stock Exchange.

Furthermore, the empirical evidence on EG is mixed. Ernst and Vitt (2000) analyze the acquisitions of 43 German companies, and find that following the acquisition, often key inventors (one third) leave the company or reduce their inventive performance (patent quality and quantity); cultural differences between the companies' R\&D departments were identified as a major factor; also, the negative innovation effect is more likely to be observed in larger firms. de Man and Duysters (2005) review the empirical literature on the innovation effects of mergers, as well as alliances; the reported effects of mergers on innovation range from neutral to negative (alliances perform much better, with most studies reporting positive effects). After reviewing the 
empirical evidence on mergers and EG, Röller et al. (2006) conclude mergers create EG only in some cases, and those gains are passed on to consumers. Using the Dutch Community Innovation Survey and the Dutch Business Register, Cefis et al. (2007) analyze the innovation effects of mergers in the context of market dominance, to find that such mergers have a positive and significant effect on innovation, but not on R\&D expenses or innovation efficiencies. Using data from the Community Innovation Survey on Dutch manufacturing firms, Cefis (2010) finds that mergers increase innovation investments and $R \& D$ intensity, and favour in-house $R \& D$ over external technology sourcing. Using data on U.S. manufacturing firms, Entezarkheir and Moshiri (2015) find that mergers boost innovation, and the effect is more pronounced for firms with a large market share.

Even at the theoretical level, however, Budzinski and Kretschmer (2007) criticize the exclusive focus of the theoretical merger literature (using the Farrell and Shapiro (1990) framework) on profitable mergers. They provide several reasons why unprofitable mergers may occur, with most or all of them not ruling out rationality. These reasons include: post-merger management issues; imperfect information; principal-agent problems; self-interested consultants; preemptive/defensive mergers; and psychological aspects. Another possible motive for merger is based on taxes through, for example, "increased utilization of tax loss and tax credit carryforwards, increased depreciation deductions obtained by stepping up the basis of assets, and increased interest deductions associated with an increase in the debt-equity ratio of the combined enterprise" (Auerbach and Reishus, 1988:159) or tax savings realized by investing funds in another firm rather than paying them as dividends to shareholders (Bierman, 1985). These elements may explain why a non-negligible proportion of mergers turn out to be unprofitable. Hence, it is important to analyze the efficiency consequences of all possible mergers, whether profitable or not.

The paper makes five contributions to the literature. First, it considers explicitly the effect of spillovers, with and without mergers. Second, in the homogeneous good model, it considers all possible mergers in oligopoly. Third, under PD, it considers both quantities and prices as strategic variables. Fourth, under PD, it considers all possible mergers in duopoly and triopoly. Finally, it focuses on unit costs and endogenous EG (as opposed to profitability, price effects or welfare). 
The paper is organized as follows. In section 2 , we study all possible mergers in a homogeneous good oligopoly. Section 3 analyzes the case of merger under QC in a duopoly with PD, extends the model to a triopoly, and considers partial and full mergers. In section 4, we analyze mergers with PC in a duopoly, and consider partial and full mergers in a triopoly. In section 5, the implications of the results for the relationship between competition and innovation, as well as merger policy, are discussed. Section 6 concludes.

\section{Homogeneous product}

There are $k \geq 2$ identical firms producing a homogeneous product and competing à la Cournot. Demand is given by $p(\mathbf{y})=A-v \sum_{i=1}^{k} y_{i}$, where $y_{i}$ denotes firm $i$ 's output, $p$ is price and $\mathbf{y} \equiv\left(y_{1}, \ldots, y_{k}\right)$. Firms produce using constant returns to scale, with the marginal cost of firm $i$ given by

$$
c_{i}=\alpha-x_{i}-\beta \sum_{j \neq i} x_{j}, \quad i=1, \ldots, k
$$

where $\alpha$ is initial marginal cost, $x_{i}$ is $\operatorname{R} \& \mathrm{D}$ output of firm $i$, and $\beta \in[0,1]$ is the $\mathrm{R} \& \mathrm{D}$ spillover rate. The profit of firm $i$ is given by

$$
\pi_{i}=\left(p-c_{i}\right) y_{i}-\gamma x_{i}^{2}, \quad i=1, \ldots, k,
$$

where $\gamma$ is an R\&D cost parameter, inversely related to the efficiency of research.

In a two-stage game, firms choose cost reducing $R \& D$ in the first stage and output in the second stage. In the Appendix we show that equilibrium unit costs in the absence of merger are given by

$$
c_{i}^{n}=\frac{\alpha v \gamma(k+1)^{2}-A[\beta(k-1)+1][k-\beta(k-1)]}{v \gamma(k+1)^{2}-k-\beta(1-\beta)(k-1)^{2}}, \quad i=1, \ldots, k
$$

The equilibrium is symmetric. ${ }^{3}$ We denote by $x^{n}$ and $c^{n}$ the equilibrium values of per firm R\&D output and unit cost, given by (33) and (3) respectively.

Unit costs in the absence of a merger are decreasing in spillovers for $\beta<0.5$ due to the

\footnotetext{
${ }^{3}$ If firms were asymmetric, EG would be even larger than what is obtained here, since by shutting down the least efficient units, the merged entity would produce using the best technology available to it.
} 
dominance of diffusion effects: for a given level of R\&D investment by competitors, a higher $\beta$ means more information is received by the firm, which contributes further to reducing its cost. Unit costs are increasing in spillovers for $\beta>0.5$ (due to the dominance of the effect of the decrease in $R \& D$ ): the higher spillover reduces the firm's as well as the competitors' $R \& D$, which pushes the firm's cost up. To see that:

$$
\frac{\partial c^{n}}{\partial \beta}=\frac{(A-\alpha) v \gamma\left(k^{2}-1\right)^{2}(2 \beta-1)}{\left[v \gamma(k+1)^{2}-k-\beta(1-\beta)(k-1)^{2}\right]^{2}} \gtreqless 0 \text { iff } \beta \gtreqless \frac{1}{2} .
$$

To understand the gains and losses involved in a change of the spillover rate, at this symmetric equilibrium, we write (1) as

$$
c(\beta)=\alpha-x(\beta)-\beta(k-1) x(\beta) .
$$

We differentiate w.r.t. $\beta$ :

$$
\frac{\partial c(\beta)}{\partial \beta}=-x^{\prime}(\beta)-\beta(k-1) x^{\prime}(\beta)-(k-1) x(\beta) .
$$

The first two terms of (6) represent the loss (in terms of cost increase) due to the increase in spillovers: the reduction in own $R \& D$, and the reduction in the competitors' $R \& D$; this loss is increasing in $\beta$. The last term represents the gain (the diffusion effect) from the increase in $\beta$ : the increase in spillovers received from competitors; this gain is decreasing in $\beta$. When $\beta<0.5$, the gain dominates (because $x$ is high), and costs decrease with $\beta$. When $\beta>0.5$, the loss dominates (because $\beta$ in the second term is high), and costs increase with $\beta$. When $\beta=0.5$, the two effects cancel out, and costs are minimized (costs are minimized when effective cost reduction, defined as $x+\beta(k-1) x$, is maximized; see Amir, 2000). This result is independent of the number of firms: an increase in $k$ simply shifts the gain and loss curves up, but they always meet at $\beta=0.5$. This means for $\beta=0.5$, unit costs are independent of the number of firms (even though per firm $R \& D$ investment decreases with the number of firms, as will be shown below).

Let $h \in\{2, \ldots, k\}$ firms merge. The number of firms becomes $k-h+1$. Following the merger, all firms are identical, and the post-merger equilibrium is also symmetric. The merged firms produce only one product, so they maintain a single research lab. Thus the profit function maintains the form it has in (2), with only one $R \& D$ expenditure per firm. If $k=h$, the market becomes a monopoly. 
Consider first the effect of the merger on $\mathrm{R} \& \mathrm{D}$ investments. The merger induces each active firm to increase its spending on R\&D:

$$
\frac{\partial x^{n}}{\partial k}=\frac{(A-\alpha)\left[\beta(k+\beta-\beta k)^{2}-(k+1) v \gamma(k(1-\beta)+3 \beta-1)\right]}{\left[v \gamma(k+1)^{2}-k-\beta(1-\beta)(k-1)^{2}\right]^{2}}<0 .
$$

The negativity of (7) follows from (35). ${ }^{4}$ After the merger, each firm is larger, values cost reduction more, and spends more on $\mathrm{R} \& \mathrm{D}$.

We can now compare unit costs with and without mergers.

Definition 1. A merger induces EG iff $c^{m}<c^{n}$.

Note that EG are determined by comparing costs, not R\&D spending, since output and welfare ultimately depend on $c$, not on $x$. Hence, in theory, mergers may increase (decrease) costs while increasing (decreasing) $\mathrm{R} \& \mathrm{D}$ spending. It should be noted that there is an apparent conflict between the elimination of duplication in $\mathrm{R} \& \mathrm{D}$ on the one hand, and increasing innovation on the other hand. The focus should be on innovation outputs (patents, new products, cost reduction), rather than on innovation inputs ( $R \& D$ spending, $R \& D$ personnel).

We have the following result:

Proposition 1.5 For any k-firm homogeneous good oligopoly with linear demand and linear costs, the merger of any number of firms $h \in\{2, \ldots, k\}$ induces an efficiency gain for the merged firms $\left(c^{m}<c^{n}\right)$, except when $\beta=0.5$ (in which case $c^{m}=c^{n}$ ). The same efficiency gain is enjoyed by outsiders, if any.

A merger induces three effects on costs. First, there is an increase in own $R \& D$, which contributes to cost reduction. Second, there is an increase in the R\&D of outsiders (if any), which

\footnotetext{
${ }^{4}$ A similar result is obtained in Lemma 1 of Matsushima et al. (2013), although in their model there are no spillovers.

${ }^{5}$ All proofs, and most computations, are in the Appendix.
} 
also contributes to cost reduction as long as $\beta>0$. The increase in own and competitors' $R \& D$ is due to the increase in concentration, which makes each firm larger, producing more output and investing more in $\mathrm{R} \& \mathrm{D}$ (higher value of cost reduction). Finally, there is a loss of spillovers from the firm(s) which has(ve) disappeared, which increases costs (as long as $\beta>0$ ). The first two effects dominate, explaining why all possible mergers reduce production costs. To better understand the effect of mergers on costs, we decompose the change in $c$. From (1), at the premerger equilibrium, we can write the cost of a firm as

$$
c=\alpha-x-\beta(k-1) x
$$

For a small exogenous change in $k$, we have that

$$
\Delta c=-\Delta x-\beta[(k-1) \Delta x+x \Delta k] .
$$

Remember that for any merger $\Delta k<0, \Delta x>0$ and $\Delta c \leq 0$. For all $\beta \neq 0.5$ we know that $\Delta c<0$ and thus

$$
-\beta x \Delta k<\Delta x[1+\beta(k-1)] .
$$

The lhs of (10) represents the loss from the merger to one firm (in terms of cost increase), which is the loss from knowledge spillovers due to the reduction in the number of firms. The rhs represents the gain from the merger (cost reduction), which comes from the increase in the R\&D of the firm and its competitors. For all $\beta \neq 0.5$ the gain exceeds the loss. For low $\beta, x$ is high but the product $\beta x$ on the lhs is small; for high $\beta, x$ is low and the product $\beta x$ on the lhs is small. Hence for almost all $\beta$, the gain exceeds the loss and costs decrease with the merger. For $\beta=0.5$, (9) is nil and thus

$$
-\frac{x \Delta k}{2}=\Delta x\left[1+\frac{k-1}{2}\right]
$$

In this case the loss exactly matches the gain. On the lhs of (11), $x$ and $\beta(=0.5)$ are both intermediate, hence their product is higher and equals the gain. In all cases, $\Delta x$ on the rhs is not very sensitive to changes in $\beta$ (although it increases with it).

The following result follows from Proposition 1.

Corollary 1. For a given number of firms pre-merger ( $k$ ), efficiency gains increase with the number of merging firms $(h)$. 
Corollary 1 indicates that EG increase when more firms join the merger, since this means there are fewer outsiders, and therefore fewer aggregate output expansion by them (i.e. less freeriding by outsiders). Moreover, more firms joining the merger means a more concentrated market, a higher output of the merged entity, a higher value of cost reduction, a greater increase in R\&D by the merged entity, and thus larger EG.

Figure 1 illustrates the unit costs with different mergers in a market composed of 10 firms. ${ }^{6}$ Unit costs are U-shaped: they initially decline with spillovers due to the benefits of greater diffusion, but eventually increase with spillovers due to the substantial decrease in $R \& D$ investments due to high spillovers (see expressions 8 and 10 above). When there is only one firm in the market, spillovers are irrelevant to $R \& D$ and unit costs. As the figure shows, when more firms join the merger, unit costs decline further, illustrating corollary 1 . The lowest costs are obtained in a monopolized market. ${ }^{7}$ All the curves meet at $\beta=0.5$; for this level of spillover, the merger has no effect whatsoever on the cost of any firm. The figure also illustrates that EG are most significant for low and high spillovers, while they are negligible for intermediate spillovers. It should be noted that a merger never raises unit costs. These results suggest a negative relationship between the number of firms and innovation.

[Figure 1 here]

Matsushima et al. (2013) mention (but do not show the results in their paper, as the published model has no spillovers) that high spillovers reduce the likelihood of mergers happening, because "mergers eliminate an opportunity for firms to exploit the spillover effects" (p. 983). In the current paper, however, we see that actually EG increase with spillovers for $\beta>0.5$. Hence, high EG do not automatically translate into more profitable mergers.

All those EG apply to insiders as well as outsiders. Investment in innovation provides a further source of free-riding for outsiders: in addition to benefiting from the output contraction of insiders and expanding their own output (Salant et al., 1983), outsiders also benefit from the

\footnotetext{
${ }^{6}$ Without loss of generality, all figures are drawn using the numerical parametrization $A=1000, \alpha=50, \gamma=60$ (and for figure 1,v=1). Changing these numbers affects the level of $R \& D$ and costs, but not the general form of the figures or the comparative statics w.r.t. spillovers or product differentiation.

${ }^{7}$ Merger to monopoly always yields the lowest possible production costs. This result also sheds light on the consequences of multiple (simultaneous) mergers. For example, in a market composed of four firms, if firms 1 and 2 merge, and firms 3 and 4 merge (resulting in a market composed of two firms), costs will decline compared with the pre-merger situation, but they will still be higher than if all firms merge together.
} 
merger through lower unit costs. However, whereas the interests of insiders and outsiders are opposed when it comes to output contraction/expansion, their interests reinforce each other when it comes to cost reduction. That is, they all benefit from the lower unit costs across the industry after the merger.

\section{Remark 1. ${ }^{8}$ With a homogeneous product:}

i) When three or more firms merge ( $h \geq 3$ ), efficiency gains are decreasing in the initial number of firms $(k)$.

ii) For all possible mergers $(h \geq 2)$, efficiency gains increase with market size $(A-\alpha)$ and decrease with research costs $(\gamma)$ and with the steepness of the demand curve $(v)$.

Remark 1 is related to the observation that innovation incentives are proportional to output, because the innovation is applied to a larger number of units. Remark $1 i$ states that for all $h \geq 3$, the merger of a given number of firms yields higher EG when the market is initially more concentrated (mathematically, for a given $h$, EG are maximized when $k=h$ ). This is due to the fact that for a given number of merging firms, a larger initial number of firms means more outsiders to the merger, which means more free-riding and output expansion by the latter, more competition post-merger, a lower output produced by the merged entity, less innovation by the latter, and thus smaller EG. Hence, not only does higher concentration reduce costs, but it also increases EG from merger. The exception is for $h=2$, where EG are maximized when $k=3$ (but after that EG decline uniformly with $k$ ); in this case the increase in effective cost reduction is higher when the market goes from a triopoly to a duopoly, than when it goes from a duopoly to a monopoly. Hence, with the exception of going from a triopoly to a duopoly $(k=3, h=2)$, numerical simulations suggest it is always the case, for all possible $h$ and $k$, that EG from merger are decreasing in the initial number of firms. More insiders, and (almost always) fewer outsiders, are good for EG.

Remark 1ii suggests that factors which increase R\&D also tend to increase EG. This is because factors which increase (decrease) $R \& D$ increase (decrease) it more when the market is

\footnotetext{
${ }^{8}$ In this paper, Remarks are based on numerical simulations.
} 
more concentrated. As the merger increases concentration, it inflates the effect of those factors on innovation. For example, it is easy to verify that $\frac{\partial x}{\partial(A-\alpha)}>0$ and (again, numerically) that $\frac{\partial^{2} x}{\partial(A-\alpha) \partial n}<0$ : innovation increases with market size, but this effect is weaker when the market is less concentrated, because the firm gets a smaller share of the market size increase. Thus, the merger, by increasing concentration and increasing the firm's market share, increases innovation incentives. In other words, market size has a positive effect on innovation with and without merger, but the effect is stronger with merger.

Similarly, $\frac{\partial x}{\partial \gamma}<0$ and (numerically) $\frac{\partial^{2} x}{\partial \gamma \partial n}>0$ : higher R\&D costs decrease innovation, but this effect is weakened as the number of firms increases, because in a more competitive market the firm invests less in innovation. Thus, higher research costs (with and without the merger) reduce innovation, but the merger, by increasing concentration, makes this effect more pronounced, generating smaller EG (a lower increase in innovation) when research costs, $\gamma$, are higher.

Finally, Remark 1ii states that EG decrease with the steepness of the demand curve, $v$. A higher $v$ means a less elastic demand, which means that a given cost reduction (which will reduce price) will generate a smaller increase in output. This effect is more pronounced when the market is more concentrated, because the firm gets a larger share of this smaller increase in output. We verify that $\frac{\partial x}{\partial v}<0$ and (numerically) $\frac{\partial^{2} x}{\partial v \partial n}>0$ : a less elastic demand reduces innovation, but this effect is weakened when the market is more competitive. As the merger increases concentration, it accentuates this effect, and a higher $v$ decreases EG.

Until this point, we have not discussed in much detail the effect of mergers on prices, profits or welfare. It is straightforward to verify (numerically) that equilibrium price is also Ushaped with respect to spillovers, with the minimum price, for any given $k$, found at $\beta=0.5$. However, prices increase with concentration. Welfare decreases with concentration and has an inverted-U shape with respect to spillovers; the spillover that maximizes welfare is decreasing in $k$ (because the negative effect of spillovers on $R \& D$ is stronger when there are more firms) and is bounded from below by $\beta=0.5$. Moreover, the spillover rate has no significant effect on the 
profitability threshold (the number of firms required for the merger to be profitable for a given market structure).

\section{Product differentiation: Quantity competition}

In this section we seek to determine how QC with differentiated products affects EG. The results are quite different from those obtained when the product is homogeneous. We start with a duopoly, and then extend the model to a triopoly.

\subsection{Duopoly}

\subsubsection{No merger}

The market is composed of two firms producing substitute goods. Demand functions are given by

$$
p_{i}(\mathbf{y})=A-y_{i}-b y_{j}, \quad i, j=1,2, \quad i \neq j,
$$

with $b \in[0,1)$ measuring PD. The profit of firm $i$ is given by

$$
\pi_{i}=\left(p_{i}-c_{i}\right) y_{i}-\gamma x_{i}^{2}, \quad i=1,2 \text {. }
$$

Cost functions are the same as in section 2 (equation 1).

In a two-stage game, firms choose $R \& D$ in the first stage and output in the second stage. In the Appendix, we show that equilibrium $R \& D$ and unit costs are given by

$$
\begin{gathered}
x_{1}^{n}=x_{2}^{n}=\frac{(A-\alpha)(2-b \beta)}{\gamma(2+b)^{2}(2-b)-(1+\beta)(2-b \beta)}, \\
c_{1}^{n}=c_{2}^{n}=\frac{\alpha \gamma(2+b)^{2}(2-b)-A(1+\beta)(2-b \beta)}{\gamma(2+b)^{2}(2-b)-(1+\beta)(2-b \beta)} .
\end{gathered}
$$

Figure 2 illustrates $\mathrm{R} \& \mathrm{D}$ as a function of $\beta$ and $b . \mathrm{R} \& \mathrm{D}$ generally decreases with

spillovers, except for very high degrees of PD ( $b=0$ or very close to zero), where $\frac{\partial x^{n}}{\partial \beta}>0$. When PD is very high, competition is softened, and the increase in spillovers reduces costs without any concern about the leakage to the other firm, inducing the now larger firm to invest more in $R \& D$ (thereby raising the value of cost reduction). But this is a very special case, which arises when 
the products are fully (or almost) independent. For example, if we take $\frac{\partial x^{n}}{\partial \beta}$ and analyze it for the parameter values given in footnote 6 (above), we find this derivative is positive only for values of $b<0.00824$, making this result essentially applicable to independent products.

[Figure 2 here]

But more importantly, as figure 2 shows, in general, R\&D decreases as PD decreases ( $b$ increases), as lower PD takes the firm further away from a "monopoly" position. The exception is when spillovers and PD are low (the north-west corner of figure 2), where R\&D actually increases as PD decreases. This is because in this case competition is very intense between firms ( $b$ is high), and $\mathrm{R} \& \mathrm{D}$ is a very effective tool to steal market share from the competitor ( $\beta$ is low, so the net own benefit from $R \& D$ is high). This effect will be important in order to understand the effect of the merger, which will be analyzed shortly.

As figure 3 shows, costs increase as PD declines, except when spillovers and PD are low, due to the effect mentioned above. Costs decline with spillovers (due to diffusion effects, in spite of the decrease in $\mathrm{R} \& \mathrm{D}$ with $\beta$ ), except when spillovers are high and $\mathrm{PD}$ is low, due to the very steep decline of $R \& D$ with spillovers in this case (see figure 2). Furthermore, intense competition due to low PD makes firms concerned about leakages to the competitor, inducing a strong negative relationship between $\mathrm{R} \& \mathrm{D}$ and spillovers.

[Figure 3 here]

Figure 3 also shows that the effect of PD on costs and R\&D is magnified by spillovers. To see this from the cost equation, using (1), at the symmetric equilibrium, $\frac{\partial c}{\partial b}=-\frac{\partial x}{\partial b}(1+\beta)$. Hence, $\operatorname{sign} \frac{\partial c}{\partial b}=-\operatorname{sign} \frac{\partial x}{\partial b}$, and a higher $\beta$ amplifies the effect of $b$. This holds without merger, and is independent of the strategic variable. It also holds under merger if there are no outsiders, but it requires that no research lab is closed.

Table 1 summarizes the effects of spillovers and PD on R\&D and costs from figures 2 and 3. 
Table 1. Effects of spillovers and PD on $R \& D$ and costs

\begin{tabular}{|c|c|c|}
\hline & Low & High \\
\hline Low & $\frac{\partial x^{n}}{\partial \beta}>0 \quad \frac{\partial x^{n}}{\partial b}<0$ & $\begin{array}{ll}\frac{\partial x^{n}}{\partial \beta}<0 & \frac{\partial x^{n}}{\partial b}>0 \\
\frac{\partial c^{n}}{\partial \beta}<0 & \frac{\partial c^{n}}{\partial b}<0\end{array}$ \\
\hline High & $\frac{\partial c^{n}}{\partial \beta}<0 \quad \frac{\partial c^{n}}{\partial b}>0$ & $\begin{array}{ll}\frac{\partial x^{n}}{\partial \beta}<0 & \frac{\partial x^{n}}{\partial b}<0 \\
\frac{\partial c^{n}}{\partial \beta}>0 & \frac{\partial c^{n}}{\partial b}>0\end{array}$ \\
\hline
\end{tabular}

\subsubsection{Merger}

Now assume those two firms merge, forming a monopolist producing two differentiated products. Here we note an important difference with the homogeneous product model in section 2. With a homogeneous product, the merged firms maintain only one research lab, since they produce only one product. In our case, however, the merged firm produces two products. These products are different, since $b<1$, by assumption. Therefore, the merged firm maintains two research facilities, one for each product. The merged firm internalizes not only the effect of its output choice on the sales of the other good, but also the effect of $R \& D$ done for a product on the cost of the other product. By merging, insiders benefit from spillovers more than outsiders. One advantage of multiproduct firms over single-product firms is that the former benefit more from technological flows within the firm: the same flows are taking place with and without merger, but with merger they are viewed as a gain (because they reduce costs and increase the total profit of the firm) and reinforce innovation, whereas without merger they are viewed as a loss (because they reduce the competitor's cost and can hurt own profits) and can hamper innovation efforts.

The profit function of the merged firm now takes the form

$$
\pi=\left(p_{1}-c_{1}\right) y_{1}+\left(p_{2}-c_{2}\right) y_{2}-\gamma\left(x_{1}^{2}+x_{2}^{2}\right) .
$$

The cost functions remain as in (1). In the Appendix we show that equilibrium R\&D outputs and unit costs under merger are given by 


$$
\begin{gathered}
x_{1}^{m}=x_{2}^{m}=\frac{(A-\alpha)(1+\beta)}{4 \gamma(1+b)-(1+\beta)^{2}}, \\
c_{1}^{m}=c_{2}^{m}=\frac{4 \alpha \gamma(1+b)-A(1+\beta)^{2}}{4 \gamma(1+b)-(1+\beta)^{2}} .
\end{gathered}
$$

It is easy to verify that $\frac{\partial x_{i}^{m}}{\partial \beta}>0$ and $\frac{\partial x_{i}^{m}}{\partial b}<0$. Here, spillovers always have a positive effect on R\&D, since the technological externality is internalized. Less PD reduces R\&D, because it reduces output and hence the benefit from cost reduction. To see that, we substitute (17) into (38) to get equilibrium output under merger: $y_{1}^{m}=y_{2}^{m}=\frac{2(A-\alpha) \gamma}{4 \gamma(1+b)-(1+\beta)^{2}}$, from which it is obvious that $\frac{\partial y_{i}^{m}}{\partial b}<0$.

It is also easy to verify that costs decrease with spillovers and PD: they decrease with spillovers since spillovers increase $\mathrm{R} \& \mathrm{D}$, and they increase with $b$ because the decrease in PD decreases R\&D, as mentioned above.

\subsubsection{Comparison}

Our goal is to compare $c^{n}$ and $c^{m}$. We have the following result.

Proposition 2. In a duopoly with quantity competition and product differentiation, a merger reduces production costs (i.e. increases $R \& D$ investments) for sufficiently high spillovers and/or product differentiation, specifically for

$$
\beta>\beta^{c, y}(b) \equiv \frac{b^{3}+2 b^{2}+4 b}{-b^{3}+2 b^{2}+8 b+8} .
$$

Figure 4 illustrates $\beta^{c, y}$ and the regions where the merger increases/decreases unit costs, by superposing $c^{m}$ and $c^{n}$. We see that the merger increases efficiency when spillovers and/or PD are sufficiently high. With high spillovers, R\&D investments without the merger are depressed, due to the significant leakage to the competitor, whereas this externality is internalized with the merger. Therefore, high spillovers contribute to generating EG, turning a negative (profit) externality into a positive one.

[Figure 4 here] 
The figure also shows that EG are more likely when PD is sufficiently high (although, as figure 4 shows, for high enough spillovers, the merger generates EG irrespective of $b$ ). When PD is low, $x^{n}$ is increasing in $b$ (see figure 2), whereas $x^{m}$ is (always) decreasing in $b$. Competition is intense between firms and they invest aggressively in R\&D; the merger relaxes this competition and increases costs. In contrast, with high $\mathrm{PD}$, competition is softened, firms invest less in $\mathrm{R} \& \mathrm{D}$ when they are independent, and the merger increases $R \& D$ and reduces costs. The two factors which boost R\&D in the absence of a merger (low $\beta$ and high $b$ ) lie behind the (northwest) region where EG do not occur in figure 4 (see figure 2 and the discussion that follows it).

The positive slope of the critical value $\beta^{c, y}$ means spillovers and PD are substitutes: either high spillovers, high PD, or both, are sufficient to generate EG. Figure 4 also illustrates that EG (the gap between the two curves) are most significant when spillovers and PD are high (the south-east region of figure 4); this is when competing firms spend the least on R\&D.

In fact, it can be easily verified (numerically) that EG, when they are present, increase with spillovers and with PD. Spillovers decrease R\&D without merger but increase it with merger, hence they amplify EG. And while in both cases R\&D increases with PD, it increases faster under merger (due to the monopolist's greater market power), amplifying EG. Conversely, EL, when present, decrease with spillovers and with PD.

We can see that EG differ significantly between the cases with homogeneous and differentiated products. Whereas with a homogeneous product mergers (almost) always generate EG and never generate EL, with differentiated products, EG result only for high enough spillovers and/or PD; otherwise, EL will occur.

\subsection{Merger of two firms in a triopoly}

In section 3.1.2 we considered mergers between two firms with QC under PD. However, in that market there were no outsiders: the whole market comprised only two firms. In this section we analyze the effect of the presence of an outsider on the results. We want to determine whether the effects of spillovers and PD carry on to markets with outsiders, and how the critical values of $b$ and $\beta$ are affected by the latter. 
Everything is as in section 3.1, except that there are three firms in the market, of which only two will merge. Demand functions are given by

$$
p_{i}(\mathbf{y})=A-y_{i}-b \sum_{j \neq i} y_{j}, \quad i=1,2,3 .
$$

Profits are the same as in (13), but with $i=1,2,3$. Cost functions are also unchanged.

In the Appendix we show that unit costs in the absence of merger are given by

$$
c_{i}^{n}=\frac{4 \alpha \gamma(1+b)(2-b)+A[4 \beta(b \beta-1)-b-2]}{\gamma\left(8+12 b-4 b^{2}\right)+4 \beta(b \beta-1)-b-2}, \quad i=1,2,3 .
$$

The general shape (but not the level) of $c^{n}$ is the same as in figure 3 , where there were only two firms in the market, and its plot is omitted.

Now let firms 1 and 2 merge. The profit of the merged firm is

$$
\pi_{1}+\pi_{2}=\left(p_{1}-c_{1}\right) y_{1}+\left(p_{2}-c_{2}\right) y_{2}-\gamma\left(x_{1}^{2}+x_{2}^{2}\right) .
$$

The profit of firm 3 is given by

$$
\pi_{3}=\left(p_{3}-c_{3}\right) y_{3}-\gamma x_{3}^{2} .
$$

The equilibrium with the merger is derived in the Appendix. The expressions for unit costs under the merger are not shown due to their analytical complexity.

Figure 5 superposes $c^{m}$ and $c^{n}$. As in section 3.1.3, it is also the case here that the merger generates EG for the merging firms when spillovers and/or PD are sufficiently high.

[Figure 5 here]

Comparing this figure with figure 4 , we observe that the presence of an outsider has shrunken the region where EG are obtained: with an outsider, the merged firms invest less in $R \& D$ than when there is no outsider (they also invest less than the outsider), hence their costs are higher. Thus, outsiders reduce the likelihood of EG.

\subsection{Full merger in a triopoly}

In order to better understand the effect of market structure on the merger outcome, in this section we consider a triopoly where firms merge to monopoly. Given that the derivation of the 
equilibrium uses the same method as in sections 3.1 and 3.2, we simply present the figure showing the regions where the merger increases/decreases costs. As figure 6 shows, the general form of the solution is the same: EG obtain for sufficiently high spillovers and/or PD. Comparing this figure with figure 4, it is clear that the line separating EG from EL has shifted left in figure 6. This indicates that it is easier to generate EG when three firms in a triopoly merge than when two firms in a duopoly merge. A larger number of firms means more intense competition premerger. Thus, there will be smaller firms and less R\&D pre-merger, whereas all externalities (both product market and technological externalities) are internalized with merger to monopoly. Hence, under QC, for merger to monopoly, a higher initial concentration reduces the likelihood of EG: a more competitive market initially means higher costs for all firms, thus the gain (in terms of cost reduction) for the post-merger monopolist is higher.

[Figure 6 here]

Furthermore, comparing figures 5 and 6 also confirms the result obtained in section 3.2: the presence of an outsider reduces the parameter space where EG are obtained, because the outsider reduces the innovation incentives of the merged firm. In other words, merging to monopoly is better (more likely to generate EG) than merging to duopoly. This is because a duopoly leaves an outsider to the merger, which reduces the innovation incentives of the merged entity, while a monopoly gives maximal innovation incentives to the merged firm. Of course, this does not necessarily mean that price is lower or welfare is higher under monopoly than under duopoly; in general, innovation incentives will not justify extreme market power.

The following Remark summarizes the previous observations.

Remark 2. With quantity competition and product differentiation:

i) Efficiency gains increase with spillovers and with product differentiation.

ii) Outsiders reduce the likelihood of efficiency gains.

iii) For merger to monopoly, higher initial concentration reduces the likelihood of efficiency gains. 
The results of this section suggest that, under QC with PD, an increase in the number of firms boosts innovation output and reduces costs only when spillovers and/or PD are sufficiently low.

Using information from figures 4 and 5, figure 7 illustrates the effect of partial versus full mergers on EG under QC. For sufficiently high (low) spillovers and PD, all (no) mergers generate EG. In a narrow region characterized by moderate/intermediate spillovers and sufficiently low PD, mergers generate EG iff there is no outsider; in this region, the internal benefits from diffusion are intermediate, and competition with the outsider is intense (because of low PD), thereby reducing the innovation incentives of the merged entity.

[Figure 7 here]

\section{Product differentiation: Price competition}

In this section we wish to determine whether the results obtained under QC extend to PC. For that purpose, we use the assumptions of section 3, except that in this section firms compete in prices. In the first stage, firms choose $R \& D$, and in the second stage they choose prices. Cost and profit functions remain unchanged from section 3.

\subsection{Duopoly}

We start with a duopoly. Inverting the demand system given by (12) yields the following demand functions (see Singh and Vives, 1984):

$$
y_{i}(\mathbf{p})=\frac{A(1-b)-p_{i}+b p_{j}}{1-b^{2}}, \quad i, j=1,2, \quad i \neq j,
$$

where $\mathbf{p} \equiv\left(p_{1}, p_{2}\right)$.

\subsubsection{No merger}

Assume that firms are independent. Solving the price stage yields the following reaction functions: 


$$
p_{i}(\mathbf{x})=\frac{A\left(2-b^{2}-b\right)+(2+b) \alpha-(2+b \beta) x_{i}-(b+2 \beta) x_{j}}{4-b^{2}}, \quad i, j=1,2, \quad i \neq j .
$$

Substituting these reaction functions into profit and maximizing w.r.t. R\&D yields the following R\&D outputs:

$$
x_{1}^{n}=x_{2}^{n}=\frac{(A-\alpha)[2-b(b+\beta)]}{\gamma(2-b)^{2}(1+b)(2+b)-(1+\beta)[2-b(b+\beta)]} .
$$

It is easy to verify here that $\mathrm{R} \& \mathrm{D}$ is increasing in $\mathrm{PD}$ and, for almost all $b>0$ (see the discussion in section 3.1.1), decreasing in spillovers. Moreover, here we do not get the peculiar result obtained in section 3.1.1, where R\&D decreased with PD for low spillovers. Even as competition intensifies due to the decline in $\mathrm{PD}$ (with low $\beta$ ), the gain from investing more in $x_{i}$ is lower under PC than under QC: this reduces both firm $i$ 's price (which is good for firm $i$ ) as well as firm $j$ 's price (which is bad for firm $i$ ) since prices are strategic complements. Under QC, the gain from investing more in $x_{i}$ is higher: it increases firm $i$ 's quantity and reduces firm $j$ 's quantity since quantities are strategic substitutes, both of which are good for firm $i$. The two effects reinforce each other under QC, whereas they partially cancel each other under PC.

In fact, comparing R\&D outputs under QC and PC (in the absence of merger) confirms this intuition. The following proposition formalizes this comparison.

Proposition 3. In a duopoly with product differentiation, $R \& D$ output is higher (and hence production costs are lower) under quantity competition than under price competition.

Vives (2008) briefly points to this possibility, but does not show it analytically. Lin and Saggi (2002) derive an equivalent result, but in their model there are no spillovers.

Substituting (26) into (1) yields equilibrium production costs in the absence of merger:

$$
c_{1}^{n}=c_{2}^{n}=\frac{(2-b)^{2}(1+b)(2+b) \alpha \gamma-(1+\beta)[2-b(b+\beta)] A}{(2-b)^{2}(1+b)(2+b) \gamma-(1+\beta)[2-b(b+\beta)]} .
$$

Figure 8 illustrates this cost. Costs increase as PD decreases: the intensification of competition due to the increase in $b$ leads to a decrease in $\mathrm{R} \& \mathrm{D}$. The effect of spillovers is more complex: it 
is negative (positive) for high (low) PD. When PD is high, R\&D decreases very little with spillovers (soft competition); hence, the diffusion effect dominates, and costs decrease with spillovers. In contrast, with low $\mathrm{PD}, \mathrm{R} \& \mathrm{D}$ decreases steeply with spillovers (intense competition); therefore, the effect of the decline in $R \& D$ dominates the diffusion effect, and costs increase with spillovers.

[Figure 8 here]

\subsubsection{Merger}

Now assume the two firms merge. Profits of the merged firm are given by equation (22). In the second stage, maximizing total profits w.r.t. prices yields

$$
p_{i}(\mathbf{x})=\frac{A+\alpha-x_{i}-\beta x_{j}}{2}, \quad i, j=1,2, \quad i \neq j .
$$

Substituting these reaction functions into total profits and maximizing w.r.t. R\&D yields

$$
x_{1}^{m}=x_{2}^{m}=\frac{(A-\alpha)(1+\beta)}{4 \gamma(1+b)-(1+\beta)^{2}} .
$$

Not surprisingly, this level of R\&D investment is the same as that which is obtained under merger with QC (section 3.2) in equation (17), given that a monopolist is indifferent between choosing prices and quantities. It follows that output and costs are also the same under merger to monopoly whether firms choose prices or quantities (for a given number of products).

\subsubsection{Comparison}

We first compare $\mathrm{R} \& \mathrm{D}$ expenditures with and without the merger. Plotting $x^{n}$ (from equation 26) and $x^{m}$ (from equation 29) shows the regions where $R \& D$ per product increases/decreases with the merger. As figure 9 shows, the merger increases R\&D except when spillovers are very low. Spillovers depress R\&D in the absence of the merger, and the merger transforms this negative effect into a positive one. With very low spillovers, the merger typically does not generate any EG. Spillovers are the major disincentive for R\&D under competition, and when they are weak, the merger reduces $R \& D$ and increases costs. 
[Figure 9 here]

Starting at a point where the merger increases costs (to the left of the boundary where $x^{m}$ and $x^{n}$ meet in figure 9), increasing or decreasing PD sufficiently makes us enter into the region where EG occur. Decreasing $b$ increases R\&D with and without the merger, but increases $\mathrm{R} \& \mathrm{D}$ faster under the merger, making us cross the boundary (moving down on the figure) into the region of EG. Symmetrically, starting from the same point, increasing $b$ decreases R\&D with and without the merger, but decreases it faster (eventually) without the merger, making us cross the boundary (moving up on the figure) into the region of EG. Hence, for a narrow range of low spillovers, the merger is more likely to generate EG when PD is either very low or very high.

The region where the merger increases $R \& D$ is exactly the region where the merger induces EG (given that the number of research labs is fixed, which was also the case in section 3, but not in section 2). We have the following result.

Proposition 4. In a duopoly with product differentiation and price competition, the merger induces efficiency gains except when spillovers are very low. Specifically, the merger induces efficiency gains when $\beta>\beta^{c, p}(b) \equiv \frac{4 b-2 b^{2}-b^{3}}{8-2 b^{2}+b^{3}}$.

The shape of this critical value of $\beta$ is exactly the boundary separating EG from EL in figure 9. As under QC, here it can also be shown that EG increase with spillovers. However, we note that EG have a U-shaped relationship with PD. This is because without the merger, R\&D increases in a concave fashion with $\mathrm{PD}$, while with the merger, $\mathrm{R} \& \mathrm{D}$ increases in a convex fashion with PD (even though monopoly output is lower, it attributes a positive value to interproduct R\&D spillovers, and benefits more at the margin from the increase in PD). And as, by definition, R\&D is higher under the merger in the region where EG occur, the gap between the two levels of $R \& D$, and thus between costs, is lowest when PD is intermediate. This also explains the curvature observed in figure 9 in the boundary separating EG from EL (see the paragraph immediately after figure 9). Similarly, EL increase with spillovers and have an inverted-U relationship with PD. 
The merger analyzed here is necessarily profitable, given that there are no outsiders. Yet, for a certain range of parameters, the merger increases costs as it softens price and $R \& D$ competition; the same type of result was obtained in section 3.1.2 under QC. Hence, under PD (at least in the absence of outsiders), mergers that increase costs may not always be harmful to firms (but will certainly hurt consumers). This result highlights the importance of performing a detailed analysis of the cost effect of mergers, in parallel to the analyses of profit and welfare effects.

The results obtained here and in section 3.1 allow us to compare EG between QC and PC. The following corollary performs this comparison.

Corollary 2. In a duopoly, EG from merger are higher, and more likely, under price competition than under quantity competition.

Given that costs are higher without the merger under PC than under QC, and post-merger costs are the same irrespective of whether the monopolist chooses quantities or prices, it follows that EG are higher under PC. (This result could also be obtained by comparing EG from equations 39 and 45; it will not necessarily hold for partial mergers, as it depends on the postmerger symmetry of PC and QC induced by merger to monopoly.) It also follows that when the merger induces EL, the loss is smaller under PC. Furthermore, comparing figures 4 and 9 (or equations 19 and 46; see the proof of Corollary 2), it is clear there are parameter combinations such that mergers induce EG under PC but induce EL under QC; however, the converse is not true. That is, $\beta^{c, y}>\beta^{c, p}$ : EG are more likely under PC than under QC. This is due to the lower value attributed to innovation under PC before the merger (as discussed above), as a result of the strategic complementarity of prices.

\subsection{Merger of two firms in a triopoly}

In this section we wish to determine whether the presence of an outsider affects the EG obtained with PC in section 4.1. Everything is as in that section, except there are three firms in 
the market, two of which merge. Inverting the demand system given by (20) yields

$$
y_{i}(\mathbf{p})=\frac{A(1-b)-(1+b) p_{i}+b \sum_{j \neq i} p_{j}}{1+b-2 b^{2}}, \quad i=1,2,3
$$

In the Appendix we show that unit costs in the absence of merger are given by

$$
c_{i}^{n}=\frac{4 \alpha \gamma\left(2+6 b^{2}+7 b\right)-A(1+b)(1+2 \beta)\left(2-b^{2}+3 b-2 b^{2} \beta-2 b \beta\right)}{4 \gamma\left(2-6 b^{2}+7 b\right)-(1+b)(1+2 \beta)\left(2-b^{2}+3 b-2 b^{2} \beta-2 b \beta\right)}, \quad i=1,2,3 .
$$

This plot is also omitted, as it is similar in shape and properties to figure 8 .

In the Appendix, we compute the equilibrium with the merger of two firms. Figure 10 plots the per product $\operatorname{R} \& D\left(x_{1}^{m}=x_{2}^{m}\right)$ of the merged firm. In this case spillovers have a double effect on the merged firm: each product benefits from the spillover from the other (own) product and from firm 3, but the firm as a whole loses from spillovers due to the leakage to firm 3 (on two products). As figure 10 shows, R\&D increases with spillovers when PD is high; in this case the merged firm is not too concerned about the leakages to firm 3, and benefits from the internal diffusion of technology and from the absorption of spillovers from firm 3 (benefiting both products 1 and 2). However, for low PD, the R\&D of the merged firm declines with spillovers; competition is intense, and the merged firm is concerned about leakages to the competitor, especially that it loses information on both $x_{1}$ and $x_{2}$, but gains only through $x_{3}$. On the other hand, the R\&D of the merged firm increases as PD increases: sales of each product increase with $\mathrm{PD}$, as does the value of cost reduction.

[Figure 10 here]

It is useful, as an aside, to examine the R\&D of the outsider. Figure 11 plots $x_{3}$ when firms 1 and 2 merge. Its behavior is similar to $x^{m}$ from figure 10, except that $\frac{\partial x_{3}}{\partial \beta}<0$ even when PD is high: as firm 3 has only one product, there are no internal benefits from spillovers, and its loss is magnified by the fact that its technology spills over to products 1 and 2. Actually, superposing figures 10 and 11 (not shown) would reveal that the outsider spends more R\&D per product than the merged entity, except for a narrow band when spillovers are very low. This is reminiscent of the effect of merger on R\&D in duopoly; see figure 9.

[Figure 11 here]

We substitute equilibrium $R \& D$ into the cost functions (1) to obtain the unit cost of the 
merged firm (see figure 12). Costs decrease steeply with spillovers when PD is high. Costs are U-shaped with spillovers when PD is low (not very visible in figure 12): they first decrease due to diffusion effects, but eventually increase with $\beta$ due to the decline of $x_{1}, x_{2}$ and $x_{3}$. Costs decrease uniformly as PD increases, as all firms increase their R\&D investments when $b$ declines.

[Figure 12 here]

Figure 12 also shows $c^{n}$ (from equation 31). This figure reveals that the merger generates EG for sufficiently high spillovers and/or PD. This result is very different from that obtained in section 4.1.3 (figure 9) (in which there was no outsider), where it was found that EG obtained except when spillovers are very low. Here, the result is more reminiscent of that obtained in section 3 with QC. It is the presence of the outsider which changes the dynamics under PC: the outsider constitutes an external sender/receiver of technology, and provides competition on the output market.

Comparing figures 5 and 12 reveals that in the presence of an outsider, the region of EG is larger under QC than under PC; the outsider dampens the innovation incentives of the merged entity in both cases, but more so under PC, because of the strategic complementarity of prices: R\&D reduces the innovator's costs and its price, to which the outsider responds by reducing its own price. The opposite happens under QC: R\&D reduces the cost and increases the output of the innovator, to which the competitor responds by reducing its output. Hence R\&D is more valuable to the innovator under QC.

Using information from figures 9 (remember that whenever there are no outsiders, the region where the merger increases $R \& D$ is exactly the same region where the merger induces EG) and 12, figure 13 indicates the region where, under PC, EG are obtained if there is no outsider, but are lost if there is an outsider. This is mainly the case when spillovers are intermediate (so the internal benefits of diffusion and the benefits received through leakages from the outsider are intermediate) and PD is sufficiently low (so the competition with the outsider is relatively intense). Hence, the presence of an outsider radically changes the EG obtained from merger under PC; EG are much less likely with outsiders present, and we can expect this result to be exacerbated with more outsiders. A similar result obtained under QC (see 
figure 7), but the region of cost-increasing mergers in the presence of outsiders is larger under PC. This is due to the strategic complementarity of prices, which reduces even further the innovation incentives of the merged entity when competition with the outsider is intense (low PD).

[Figure 13 here]

\subsection{Full merger in a triopoly}

In this section we analyze a triopoly with PC where firms merge to monopoly. Given that the analysis is similar to that in sections 4.1 and 4.2 , we simply present graphically the comparison between unit costs with and without the merger. Figure 14 shows costs with no merger versus costs when all three firms merge. The merger induces EG except when spillovers are very low. The shape of the boundary separating EG from cost increases is similar to its shape in figure 9 in section 4.1.3 (where there were no outsiders), but different from its shape in figure 12 in section 4.2 (where there was one outsider). Hence, under PC, when there are no outsiders, we expect the merger to induce EG except when spillovers are very low; when there are outsiders, we expect EG from the merger when spillovers and/or PD are sufficiently high. The difference between the two cases is that for intermediate spillovers and low enough PD (see figure 13), the merger induces EG when there are no outsiders, but induces EL when there are outsiders.

[Figure 14 here]

Comparing figures 9 and 12, and also figures 12 and 14 reveals that the presence of an outsider reduces the likelihood of EG (just as under QC). Comparing figures 9 and 14 shows that for merger to monopoly, higher initial concentration increases the likelihood of EG; this is the opposite of what was observed under QC.

The following Remark summarizes the previous observations.

\section{Remark 3. With price competition and product differentiation:}


i) Efficiency gains increase with spillovers, and have a U-shaped relationship with product differentiation.

ii) Outsiders reduce the likelihood of efficiency gains.

iii) For merger to monopoly, higher initial concentration increases the likelihood of efficiency gains.

Finally, comparing the figure pairs 4-9, 5-12 and 6-14 suggests the following result:

Remark 4. With product differentiation, merger to monopoly induces a higher likelihood of efficiency gains under price competition than under quantity competition, while the opposite is true for partial mergers.

The result in Remark 4 comes from the low investments in R\&D under PC pre-merger (see Proposition 3) and the intense competition from outsiders post-merger under PC. For merger to monopoly, the final outcome is the same under QC and PC. The low R\&D under PC premerger is a result of the fact that prices are strategic complements and $R \& D$ reduces costs and prices (especially the competitor's price), which reduces the profitability of R\&D compared with $\mathrm{QC}$, where quantities are strategic substitutes. This implies that the likelihood of EG is higher under PC. For partial mergers, EG disappear under PC with intermediate spillovers (limited benefits received from the outsider post-merger) and with low PD (intense competition with the outsider) (see the discussion that follows figure 12). Thus, for such mergers, mergers under QC are more likely to generate EG. The same factor is at play here for both types of mergers under PC: it is the strategic complementarity of prices combined with the presence of a competitor which reduces R\&D investments pre-merger under PC, and which reduces investment in a partial merger under PC.

The following table summarizes the main results obtained under the different models. 
Table 2. Effect of merger on costs

\begin{tabular}{|l|c|c|c|}
\hline Merger of $h / k$ firms induces EG if & $2 / 2$ & $2 / 3$ & $3 / 3$ \\
\hline Homogeneous product & \multicolumn{3}{|c|}{ Always } \\
\hline PD - Quantity competition & \multicolumn{3}{|c|}{$\beta$ and/or PD high } \\
\hline PD - Price competition & $\beta$ moderate/high & $\beta$ and/or PD high & $\beta$ moderate/high \\
\hline
\end{tabular}

Table 3 provides a numerical example comparing the models with homogeneous product, QC and PC. We note that 1) EG are positive but more limited with a homogeneous product; 2) with PD, partial mergers (may) induce an EL; and 3) EG are largest under PC, but this setting also generates the largest EL under partial mergers.

Table 3. Comparison between the three settings through an example

\begin{tabular}{|c|l|c|c|c|}
\hline & & $2 / 2$ & $2 / 3$ & $3 / 3$ \\
\hline \multirow{2}{*}{$\begin{array}{c}\text { Homogeneous good } \\
\text { Quantity competition }\end{array}$} & Merger & $c^{m}=46.0251$ & $c^{m}=46.0428$ & $c^{m}=46.0251$ \\
(with PD) & Merger & $c^{m}=45.899$ & $c^{m}=46.1993$ & $c^{m}=45.3975$ \\
& & $\mathrm{EG}=0.0177$ & $\mathrm{EG}=0.0222$ & $\mathrm{EG}=0.0399$ \\
\hline \multirow{2}{*}{ Price competition } & No merger & $c^{n}=47.2324$ & $c^{n}=47.3986$ & $c^{n}=47.3986$ \\
(with PD) & Merger & $c^{m}=45.899$ & $c^{m}=47.5756$ & $c^{m}=45.3975$ \\
& & $\mathrm{EG}=1.3334$ & $\mathrm{EG}=-0.177$ & $\mathrm{EG}=2.0011$ \\
\hline
\end{tabular}

Notes: The example is constructed with $\beta=0.4, b=0.9$. A positive (negative) number indicates an EG (EL).

\section{The competition-innovation relationship and antitrust policy}

The results derived in this paper relate to the everlasting debate on the relationship between competition and innovation. The results here are interpreted regarding the relationship between competition and innovation outputs (effective cost reduction), not innovation inputs (R\&D expenditure). For example, Vives (2008) examines this question, but he focuses on 
innovation inputs. An intensification of competition can take at least two forms: an increase in the number of firms (the opposite of a merger), and a decrease in PD (an increase in $b$ ).

The results suggest a negative relationship between competition (an increase in the number of firms) and innovation with homogeneous products, as unit costs increase with the number of active firms (see figure 1 and Proposition 1).

The effect of an increase in the number of firms under PD on innovation output is more complex. As shown above, such an intensification of competition reduces costs when spillovers and/or PD are sufficiently low (implying a positive relationship between competition and innovation); otherwise, the increase in the number of firms under PD increases costs when spillovers and/or PD are sufficiently high (implying a negative relationship). As for the decrease in PD, all models in sections 3 and 4 point to a generally negative relationship between competition (decrease in PD) and innovation outputs: unit costs increase as PD decreases (except when spillovers and PD are low under QC; see figure 3).

The following table summarizes the relationship between competition and innovation as predicted by the model. The rows represent different types of product market interactions, while the columns represent an increase in the number of firms $(k)$ and a decrease in PD. As the table suggests, the sign of the relationship depends on at least six factors: a) whether there is PD or not; b) whether firms compete in prices or quantities; c) whether spillovers are low or high; d) whether the initial level of PD is low or high; e) the initial number of firms (under PC); and f) whether the intensification of competition takes the form of an increase in the number of firms or a decrease in PD. The picture would become even more multifaceted if one also looked at innovation inputs, not only innovation outputs. And if we add fixed (production and/or research) costs to the model, the (sometimes) positive signs resulting from an increase in the number of firms in table 4 would eventually turn negative (for a sufficiently high number of firms), generating an inverted-U relationship between innovation output and the number of firms. Hence, the results point to a complex relationship between competition (broadly defined) and innovation outputs, which is consistent with the inconclusiveness of empirical studies of this relationship. However, in the models studied here, the relationship is more often (i.e. for a wider range of parameters) negative than positive. 
Table 4. Effect of the intensification of competition on innovation output

\begin{tabular}{|c|c|c|}
\hline & $k \uparrow$ & PD $\downarrow$ \\
\hline Homogeneous product & \multicolumn{2}{|c|}{ NA } \\
\hline Quantity competition with PD & \multicolumn{2}{|c|}{$\begin{array}{r}\text { low } \beta \text { and/or low PD: + } \beta \text { and/or high PD: - } \\
\text { Price competition with PD }(k \geq 2)\end{array}$} \\
\hline high $\beta$ and/or high PD: - & \\
\hline
\end{tabular}

Furthermore, to better understand the consequences of EG, it is important to clearly identify them. For example, the Canadian Merger Enforcement Guidelines mention three categories of efficiencies to be considered: allocative, productive, and dynamic efficiencies. Additionally, the efficiency effects must be made explicit and must not be lumped together with other effects (as would be the case by using only a total welfare standard). That is, "the assessment of the competitive effects of the merger under section 92 of the Act is to be segregated from the evaluation of efficiency gains under section 96" (Competition Bureau, 2011:38). This separation allows antitrust authorities to better address the trade-offs between anticompetitive effects and EG. Strohm (2004:4) also stresses the importance of clearly identifying EG:

"The Williamson Trade-Off, which forms the theoretical basis for efficiency analysis within economic theory, provides a good illustration of the idea that a decision based on the proposed criteria can only be reached when the opposing effects, namely allocative inefficiencies (welfare losses through monopolization) and productive efficiency (welfare gains through cost savings) of the merger in question can be precisely determined."

Yet, as Encaoua and Hollander (2002) note, U.S. competition policy traditionally focuses more on allocative and productive efficiency than on dynamic efficiency effects, which are more difficult to assess. As Kern (2015:33) asserts: "the efficiency defense has to be regarded as even more important in connection with the protection of innovation competition." A related approach is innovation market analysis; on this, see Gilbert and Sunshine (1995) and, for a recent discussion, Kern (2015).

The current paper did not consider price or welfare effects. Most academic articles on mergers use the total welfare standard to determine whether a merger should be approved or not. 
However, antitrust authorities use different combinations of several criteria/variables in merger analysis: total welfare, consumer welfare, weighted welfare, market shares, EG, effect on innovation, entry barriers, buyer power, other social/political objectives such as employment or international competitiveness, etc. ${ }^{9}$ As Stennek and Verboven (2006:242) write: "Depending on which policy objective one has in mind, the total cost savings should be evaluated differently". Ávalos (2010) reviews how EG are evaluated in a number of jurisdictions, and concludes "that the different countries differ in their objectives" (p. 368). Therefore, relying exclusively on total welfare overlooks many aspects which are considered important by antitrust authorities.

This paper also does not take a stand on which welfare standard should be used in assessing mergers, ${ }^{10}$ or whether EG have to be passed on to consumers. Rather, its goal is to identify the foundations of endogenous EG as clearly as possible, and allow the different jurisdictions (or different authors), who are potentially using different standards, to reach their own conclusions regarding the social desirability of a merger. EG are neither necessary nor sufficient for a merger to be profitable and/or socially beneficial. The paper points out that total welfare analysis, as used by a large proportion of studies, is an important but insufficient step, in that it lumps together elements (market power effects, allocative/productive/dynamic efficiency effects, etc.) that antitrust authorities need to be able to identify separately. In focussing only on profitable mergers and using the total welfare standard, studies 1) neglect unprofitable mergers which may nonetheless be submitted for approval, as there are theoretical arguments and empirical evidence (see the introduction) that at least some mergers will be unprofitable; and 2) disregard the fact that antitrust authorities may wish to use a different standard from total welfare (price standard, weighted welfare standard, Hillsdown standard, etc.). Even within the same country more than one standard may be used; for example, the Swedish competition authority uses the consumer surplus standard, while the Swedish Courts use total surplus (Röller et al., 2006).

As it does not adopt a specific welfare standard, this paper also does not make specific policy recommendations. Nonetheless, the results allow us to make the following points

\footnotetext{
${ }^{9}$ Bian and McFetridge (2000) calculate, in a homogeneous good framework, the minimal efficiencies required for a merger to satisfy different welfare standards under Canadian competition law.

10 "The decision which welfare standard shall apply can not be reached through welfare theory itself, but must be decided normatively. Practically, this means that the decision is a political one." (Strohm, 2004:4).
} 
regarding merger policy. We presume that ceteris paribus, the higher the EG from a merger, the more likely will this merger be approved, irrespective of the welfare standard used (one exception may be when there is a concern about exit of competitors [efficiency offense], although that should be understood to be part of the ceteris paribus). First, for homogeneous products, mergers in industries with intermediate spillovers are harder to justify from an efficiency point of view, as the EG are more limited in this case. Second, if the question with homogeneous products is how large the EG will be, with PD we have to ask a more fundamental question: will the merger result in EG or EL? The paper suggests EL may result when spillovers and PD are low (this is the worst of all possible worlds, as the EL exacerbate the negative anticompetitive effects of mergers). As a result, merger proposals in such markets should be doubly scrutinized.

\section{Conclusion}

This paper has analyzed endogenous EG from mergers between firms with ex ante identical costs through cost-reducing R\&D, with and without PD. With a homogeneous good, all possible mergers were shown to generate EG: the effect of the increase in R\&D by the merged entity and by outsiders (due to the increase in concentration) dominates the loss of the R\&D of the firms which have "disappeared" following the merger. EG are most significant for very low and very high spillovers. Moreover, EG increase with the number of insiders and (almost always) decrease with the number of outsiders. After that, PD was introduced. It was shown that higher spillovers and higher PD generally increase the likelihood of EG; this is the case under QC, and under PC if there are outsiders. This is because with high spillovers, R\&D investments without merger are depressed, as a result of the significant leakage to the competitor, whereas this externality is internalized with the merger. Furthermore, with high PD, competition is softened, firms invest less in $R \& D$ when they are independent, and mergers increase $R \& D$ and reduce costs.

With PC and merger to monopoly, mergers generate EG except for very low spillovers. The effect of spillovers is different between the homogeneous good model and the model with PD; this is because with a homogeneous good, the merged firm maintains only one research lab, 
whereas with PD the merged firm maintains a separate research lab for each product. Furthermore, under PD, it was shown that 1) the presence of an outsider reduces the likelihood of $\mathrm{EG}$; 2) for merger to monopoly under QC (PC), higher initial concentration reduces (increases) the likelihood of EG; 3) merger to monopoly is more likely to induce EG under PC than under QC, while the opposite is true for partial mergers; and 4) EG increase with R\&D spillovers, but may increase or decrease with PD. Moreover, QC yields higher R\&D and lower EG from merger than PC (in a duopoly with PD).

The usefulness of the approach followed in this paper is underlined by the asymmetry that exists between EG and EL: firms will use an efficiency defense when (they can argue that) there are expected EG, but they will not mention EL when they think (or know) that the merger may raise costs. Antitrust authorities need to scrutinize the possible cost effects of mergers, whether firms point to them or not. A merger which would (unusually) reduce prices absent cost effects may increase prices due to EL.

Dynamic EG, like the ones considered here, will not materialize immediately after the merger. They are more likely to arise over the medium term, where the firm gets time to do research and implement the new technological discoveries. Also, when attempting to assess EG ex post, as the comparison is with a hypothetical cost (that would have been obtained if no merger has taken place), it is difficult for researchers, and even for the firm, to evaluate such EG with certainty. Computer-based simulations can be used by antitrust authorities to model potential EG (Röller et al., 2006). Röller et al. conclude that "the presence and magnitude of efficiency gains may need to be examined on a case-by-case basis" (2006:112). Furthermore, in merger assessment, expected dynamic EG have to be added to other types of expected EG (due to economies of scale, rationalization, etc.).

The result that the innovation effects of mergers depend on spillovers, which was verified for all models studied in this paper, is related to the literature on mergers of firms producing substitutes or complements (see, for example, Economides and Salop, 1992; Gaudet and Salant, 1992; Brito and Catalão-Lopes, 2010), since a rival's R\&D may act as a substitute or complement to own R\&D, depending on the spillover level.

If alternatives to mergers can yield EG, they may be socially preferable. For example, 
analyzing the semiconductor industry, Gugler and Siebert (2007) find both mergers and RJVs raise the market shares of insiders, but RJVs induce a larger increase in market share. Hence, in many cases RJVs may be viable alternatives to mergers, while avoiding their anticompetitive effects (see also Sawler (2005) on this topic). An additional advantage of RJVs is that they do not entail the closure of some research labs (which occurs under merger with a homogeneous product). Furthermore, one result from the precompetitive $R \& D$ literature is that $R \& D$ cooperation boosts innovation (inputs) when spillovers (d'Aspremont and Jacquemin, 1988) and/or PD are sufficiently high. As shown in the current paper, with PD, a related result obtains: mergers are more likely to induce EG when spillovers and/or PD are sufficiently high (under QC, and also under PC when there is no outsider). The impacts of R\&D cooperation and mergers are affected similarly by $R \& D$ spillovers when the number of research labs is unchanged, since both entail the internalization of a technological externality (it can be shown that in duopoly with PD, merger entails a wider range of parameters for which EG obtain than RJVs, implying the two strategies are not equivalent). Another alternative to merger is specialization in the presence of diseconomies of scope (see Stennek and Verboven, 2006). A further alternative is divesture, which leads to the selection of the more socially profitable mergers (Ávalos, 2010).

An important avenue for future research, which is mentioned by Teppermand and Sanderson (2007), is the effect of mergers on future products and future firms. This is particularly challenging, as even the merging firms may not have complete information about such hypothetical effects (on this issue, as well as other important interactions between merger policy and innovation, see Katz and Shelanski, 2004). Second, as only duopolies and triopolies were considered under PD in this paper, a generalization of the results to more general market structures would be useful. Third, here we considered process R\&D; the effect of mergers on product R\&D should also be analyzed. Finally, generalizing the results obtained here by weakening the assumptions on preferences and returns to scale is also a promising avenue of inquiry. 


\section{References}

Amel, D., Barnes, C., Panetta, F., and Salleo, C. (2004) Consolidation and efficiency in the financial sector: A review of the international evidence. Journal of Banking \& Finance. 28(10):2493-2519.

Amir, R. (2000) Modelling imperfectly appropriable R\&D via spillovers. International Journal of Industrial Organization. 18(7):1013-1032.

Atallah, G. (2005) R\&D and Merger Profitability. Seoul Journal of Economics. 18(4):325-354.

Auerbach, A.J., and Reishus, D. (1988) The Effects of Taxation on the Merger Decision. In Auerbach, A.J. (ed.) Corporate Takeovers: Causes and Consequences. University of Chicago Press.

Ávalos, M. (2010) Merger Policy and Efficiency Gains. economía mexicana NUEVA ÉPOCA. 19(2):343-376.

Ávalos, M. and De Hoyos, R.E. (2008) An Empirical Analysis of Mexican Merger Policy. Review of Industrial Organization. 32(2):113-130.

Banal-Estañol, A., Macho-Stadler, I., and Seldeslachts, J. (2008) Endogenous mergers and endogenous efficiency gains: The efficiency defence revisited. International Journal of Industrial Organization. 26(1):69-91.

Bian, L., and McFetridge, D.G. (2000) The Efficiencies Defence in Merger Cases: Implications of Alternative Standards. Canadian Journal of Economics. 33(2):297-318.

Bierman, H. (Jr.) (1985) A Neglected Tax Incentive for Mergers. Financial Management. 14(2):29-32.

Brito, D., and Catalão-Lopes, M. (2010) Mergers of Producers of Complements: How Autonomous Markets Change the Price Effects. The Manchester School. 78(1):60-75.

Budzinski, O., and Kretschmer, J.-P. (2007) Implications of unprofitable horizontal mergers: a re-interpretation of the Farrell-Shapiro-Framework. Marburger volkswirtschaftliche Beiträge. No. 2007,14.

Cabolis, C., Manasakis, C., and Petrakis, E. (2005) Mergers, Acquisitions and Firms' R\&D Incentives.

Cabolis, C., Manasakis, C., and Petrakis, E. (2008) Horizontal Mergers and Acquisitions with Endogenous Efficiency Gains. BE.NE.TeC. Working Paper 2008-17. Department of Economics. University of Crete.

Cefis, E. (2010) The impact of M\&A on technology sourcing strategies. Economics of Innovation and New Technology. 19(1):27-51.

Cefis, E., Sabidussi, A., and Schenk, H. (2007) Do Mergers of Potentially Dominant Firms foster Innovation? Discussion Paper Series nr: 07-20. Tjalling C. Koopmans Research Institute. Utrecht School of Economics. Universiteit Utrecht.

Coate, M.B. (2005) Efficiencies in Merger Analysis: An Institutionalist View. Supreme Court Economic Review. 13:189-240.

Competition Bureau (2011) Merger Enforcement Guidelines. Industry Canada.

Cunha, M., Sarmento, P., and Vasconcelos, H. (2014) Uncertain Efficiency Gains and Merger Policy. FEP Working Paper n. 527. School of Economics and Management. University of Porto.

Cunha, M., and Vasconcelos, H. (2015) Mergers in Stackelberg Markets with Efficiency Gains. Journal of Industry, Competition and Trade. 15:105-134. 
d'Aspremont, C., and Jacquemin, A. (1988) Cooperative and Noncooperative R\&D in Duopoly with Spillovers. The American Economic Review. 78(5):1133-1137.

Davidson, C., and Ferret, B. (2007) Mergers in Multidimensional Competition. Economica. 74(296):695-712.

de Bettignies, J.-E., and Ross, T.W. (2014) Mergers, Agency Costs, and Social Welfare. Journal of Law, Economics, \& Organization. 30(2):401-436.

de Man, A.-P. and Duysters, G. (2005) Collaboration and innovation: a review of the effects of mergers, acquisitions and alliances on innovation. Technovation. 25(12):1377-1387.

Economides, N., and Salop, S. (1992) Competition and Integration among Complements, and Network Market Structure. Journal of Industrial Economics. 40(1):105-123.

Encaoua, D., and Hollander, A. (2002) Competition Policy and Innovation. Oxford Review of Economic Policy. 18(1):63-79.

Entezarkheir, M., and Moshiri, S. (2015) Merger Induced Changes of Innovation: Evidence from a Panel of U.S. Firms.

Ernst, H., and Vitt, J. (2000) The influence of corporate acquisitions on the behaviour of key inventors. R\&D Management. 30(2):105-119.

Ferrer, R.C. (2011) An Empirical Investigation of the Effects of Merger and Acquisition on Firm's Profitability. Proceedings. Allied Academies International Conference. Academy of Studies in International Business. Las Vegas, Nevada. October 12-15. 11(2):9-10.

Gaudet, G., and Salant, S.W. (1992) Mergers of Producers of Perfect Complements Competing in Price. Economics Letters. 39(3):359-364.

Gilbert, R.J., and Sunshine, S.C. (1995) Incorporating Dynamic Efficiency Concerns in Merger Analysis: The Use of Innovation Markets. Antitrust Law Journal. 63(2):569-601.

Gugler, K., and Siebert, R. (2007) Market Power versus Efficiency Effects of Mergers and Research Joint Ventures: Evidence from the Semiconductor Industry. The Review of Economics and Statistics. 89(4):645-659.

Hogarty, T.F. (1970) Profits from Merger: The Evidence of Fifty Years. St. John's Law Review. 44(5):378-391.

Jost, P.-J., and van der Velden, C. (2006) Mergers in Patent Contest Models with Synergies and Spillovers. Schmalenbach Business Review. 58:157-179.

Jovanovic, D. (2014) Mergers, Managerial Incentives, and Efficiencies. Discussion Paper No 88. Düsseldorf Institute for Competition Economics.

Katz, M.L., and Shelanski, H.A. (2004) Merger Policy and Innovation: Must Enforcement Change to Account for Technological Change? In Jaffe, A.B., Lerner, J., and Stern, S. (eds.) Innovation Policy and the Economy. Volume 5. The MIT Press.

Kern, B.R. (2015) Innovation Markets, Future Markets, or Potential Competition: How Should Competition Authorities Account for Innovation Competition in Merger Reviews?

Kleer, R. (2012) The effect of mergers on the incentive to invest in cost-reducing innovations. Economics of Innovation and New Technology. 21(3):287-322.

Le Pape, N., and Zhao, K. (2012) Mergers and uncertainty in Stackelberg game.

Lin, P., and Saggi, K. (2002) Product differentiation, process R\&D, and the nature of market competition. European Economic Review. 46(1):201-211.

Matsushima, N., Sato, Y., and Yamamoto, K. (2013) Horizontal Mergers, Firm Heterogeneity, and R\&D Investments. The B.E. Journal of Economic Analysis \& Policy. 13(2):959-990.

Monti, M. (2006) Foreword. In Ilzkovitz, F., and Meiklejohn, R. (eds.) European Merger 
Control: Do We Need an Efficiency Defense? Edward Elgar, Cheltenham, UK.

Motis, J., Neven, D., and Seabright, P. (2006) Efficiencies in merger control. In Ilzkovitz, F., and Meiklejohn, R. (eds.) European Merger Control: Do We Need an Efficiency Defense? Edward Elgar, Cheltenham, UK.

Röller, L.-H., Stennek, J., and Verboven, F. (2006) Efficiency gains from mergers. In Ilzkovitz, F., and Meiklejohn, R. (eds.) European Merger Control: Do We Need an Efficiency Defense? Edward Elgar, Cheltenham, UK.

Salant, S.W., Switzer, S., and Reynolds, R.J. (1983) Losses from horizontal merger: The effects of an exogenous change in industry structure on Cournot-Nash equilibrium. Quarterly Journal of Economics. 98(2):185-199.

Sawler, J. (2005) Horizontal alliances and the merger paradox. Managerial and Decision Economics. 26(4):243-248.

Singh, N., and Vives, X. (1984) Price and quantity competition in a differentiated duopoly. RAND Journal of Economics. 15(4):546-554.

Slaughter and May (2012) The EU Merger Regulation: An overview of the European merger control rules.

Stenbacka, L.R. (1991) Mergers and investments in cost reduction with private information. International Journal of Industrial Organization. 9(3):397-405.

Stennek, J., and Verboven, F. (2006) Merger control and enterprise competitiveness: empirical analysis and policy recommendations. In Ilzkovitz, F., and Meiklejohn, R. (eds.) European Merger Control: Do We Need an Efficiency Defense? Edward Elgar, Cheltenham, UK.

Strohm, A. (2004) Efficiencies in Merger Control: All you Always Wanted to Know and Were Afraid to Ask. Directorate-General for Competition. European Commission.

Tombak, M. (2002) Mergers to monopoly. Journal of Economics \& Management Strategy. 11(3):513-546.

U.S. Department of Justice and the Federal Trade Commission (2010) Horizontal Merger Guidelines.

Vives, X. (2008) Innovation and Competitive Pressure. Journal of Industrial Economics. 56(3):419-469.

Werden, G.J., Froeb, L.M., and Tschantz, S. (2005) The Effects of Merger Efficiencies on Consumers of Differentiated Products. European Competition Journal. 1(2):245-264.

Williamson, O.E. (1968) Economies as an Antitrust Defense: The Welfare Tradeoffs. The American Economic Review. 58(1):18-36.

Yde, P.L., and Vita, M.G. (1996) Merger Efficiencies: Reconsidering the "Passing-on" Requirement. Antitrust Law Journal. 64(3):735-747. 


\section{Appendix}

\section{Computations for section 2}

In the first stage, firms choose R\&D simultaneously. In the second stage, they choose outputs. Starting with the second stage, maximizing profits w.r.t. output yields the following reaction functions:

$$
y_{i}(\mathbf{x})=\frac{A-\alpha+[k-\beta(k-1)] x_{i}-(1-2 \beta) \sum_{j \neq i} x_{j}}{v(k+1)}, \quad i=1, \ldots, k,
$$

where $\mathbf{x} \equiv\left(x_{1}, \ldots, x_{k}\right)$. Substituting these reaction functions into profit and solving the first stage yields equilibrium R\&D outputs:

$$
x_{i}^{n}=\frac{(A-\alpha)[k-\beta(k-1)]}{v \gamma(k+1)^{2}-k-\beta(1-\beta)(k-1)^{2}}, \quad i=1, \ldots, k,
$$

where the superscript $n$ stands for "no merger".

It is well known that in this model (noncooperative) $R \& D$ investments of each firm decrease with spillovers: from (33) we have that

$$
\frac{\partial x^{n}}{\partial \beta}=\frac{(A-\alpha)(k-1)\left[[k-\beta(k-1)]^{2}-v \gamma(k+1)^{2}\right]}{\left[v \gamma(k+1)^{2}-k-\beta(1-\beta)(k-1)^{2}\right]^{2}}<0 .
$$

The negativity of (34) follows from the second order condition on the choice of R\&D:

$$
\frac{\partial^{2} \pi_{i}}{\partial x_{i}^{2}}=\frac{2[k(1-\beta)+\beta]^{2}}{v(k+1)^{2}}-2 \gamma<0
$$

Substituting (33) into (1) yields equilibrium unit costs in the absence of merger, given by (3).

\section{Proof of Proposition 1.}

$$
\frac{\partial c^{n}}{\partial k}=\frac{(A-\alpha) v \gamma(1-2 \beta)^{2}\left(k^{2}-1\right)}{\left[v \gamma(k+1)^{2}-k-\beta(1-\beta)(k-1)^{2}\right]^{2}} .
$$

(36) is strictly positive for all $\beta \neq 0.5$ and nil for $\beta=0.5$. Given that any merger reduces $k$, it follows that any merger reduces costs, except at $\beta=0.5$ where costs remain unchanged. 


\section{Proof of Corollary 1.}

A higher number of merging firms means a lower post-merger number of firms, and from (36) this implies lower costs for all firms.

\section{Computations for section 3.1.1}

Solving the second (output) stage yields the following reaction functions:

$$
y_{i}(\mathbf{x})=\frac{(A-\alpha)(2-b)+(2-b \beta) x_{i}+(2 \beta-b) x_{j}}{4-b^{2}}, \quad i=1,2, \quad i \neq j .
$$

Substituting these reaction functions into profit and solving the R\&D stage yields (14). Substituting (14) into the cost functions (1) yields unit costs in the absence of merger, given by (15).

To see that $\frac{\partial x^{n}}{\partial \beta}>0$ when products are independent, we evaluate (from equation 14) $\left.\left.\frac{\partial x^{n}}{\partial \beta}\right|_{b=0}=\frac{4(A-\alpha)}{\left(8 \gamma-2(1+\beta)^{2}\right.}>0\right)$. To see that R\&D actually increases as PD decreases when spillovers and PD are low (the north-west corner of figure 2), we evaluate $\left.\frac{\partial x^{n}}{\partial b}\right|_{\beta=0}=\frac{2(A-\alpha) \gamma\left(3 b^{2}+4 b-4\right)}{\left(2+(b+2)^{2}(b-2) \gamma\right)^{2}}$, which is positive for $b>\frac{2}{3}$.

\section{Computations for section 3.1.2}

Solving the output stage yields the following reaction functions:

$$
y_{i}(\mathbf{x})=\frac{(A-\alpha)(1-b)+(1-b \beta) x_{i}+(\beta-b) x_{j}}{2\left(1-b^{2}\right)}, \quad i, j=1,2, \quad i \neq j .
$$

Substituting (38) into profit and maximizing the latter w.r.t. R\&D yields (17). Substituting (17) into the cost function (1) yields unit costs under merger (18).

\section{Proof of Proposition 2.}

Taking the difference between $c^{m}$ and $c^{n}$ yields 


$$
c^{m}-c^{n}=\frac{(A-\alpha) \gamma(1+\beta)\left[b^{3}+2 b^{2}+4 b-\beta\left(-b^{3}+2 b^{2}+8 b+8\right)\right]}{\left[\gamma(2+b)^{2}(2-b)-(1+\beta)(2-b \beta)\right]\left[4 \gamma(1+b)-(1+\beta)^{2}\right]} .
$$

The denominator of this expression is the product of the denominators of (15) and (18), therefore it is positive, and the sign of the whole expression hinges upon the sign of the numerator. Setting the latter equal to zero and solving for $\beta$ yields the critical value $\beta^{c, y}$ given in (19). For $\beta>\beta^{c, y}$, $c^{m}<c^{n}$, while for $\beta<\beta^{c, y}, c^{m}>c^{n}$. Given that the number of research labs is unchanged, higher costs automatically mean lower R\&D investments.

\section{Computations for section 3.2}

No merger

Solving the output stage yields

$$
y_{i}(\mathbf{x})=\frac{(A-\alpha)(2-b)+[2+b(1-2 \beta)] x_{i}+(2 \beta-b) \sum_{j \neq i} x_{j}}{2(2-b)(1+b)}, \quad i=1,2,3 .
$$

Substituting these reaction functions into profit and letting each firm choose its $R \& D$ to maximize its profits yields the following R\&D outputs under competition:

$$
x_{i}^{n}=\frac{(A-\alpha)[2+b(1-2 \beta)]}{\gamma\left(8+12 b-4 b^{2}\right)+4 \beta(b \beta-1)-b-2}, \quad i=1,2,3
$$

Substituting these R\&D outputs into the cost functions (1) yields (21).

Merger

Cost functions are unchanged. Solving the output stage yields the following reaction functions:

$$
\begin{gathered}
y_{i}(\mathbf{x})=\frac{2(A-\alpha)(2-b)(1-b)+\left[4-6 b \beta-3 b^{2}(1-\beta)\right] x_{i}+\left[b^{2}(1+\beta)+2 \beta(2-b)-4 b\right] x_{j}+2\left[b^{2}-b+2 \beta(1-b)\right] x_{3}}{4\left[2-(3-b) b^{2}\right]}, \\
y_{3}(\mathbf{x})=\frac{2(A-\alpha)+[2 \beta-b(1-\beta)]\left(x_{1}+x_{2}\right)+2[1+b(1-\beta)] x_{3}}{2\left(2+2 b-b^{2}\right)} .
\end{gathered}
$$

Substituting these reaction functions into profit and maximizing the latter w.r.t. R\&D yields R\&D outputs under merger $x_{1}^{m}=x_{2}^{m}$ (which we denote $x^{m}$ ) and $x_{3}$. Substituting these R\&D outputs into the cost functions yields the marginal costs $c_{1}^{m}=c_{2}^{m}$ (which we denote $c^{m}$ ) and $c_{3}$. Due to the analytical complexity of the results, we do not present here the analytical solutions for 
$x^{m}$ and $c^{m}{ }^{11}$

\section{Proof of Proposition 3.}

Let $x^{n, y}$ denote R\&D output under QC (from equation 14), and $x^{n, p}$ denote R\&D output under PC (from equation 26). Taking the difference yields

$$
x^{n, y}-x^{n, p}=\frac{(A-\alpha) \gamma b^{3}\left(4-b^{2}\right)(1+\beta)}{\left[\gamma(2+b)^{2}(2-b)-(1+\beta)(2-b \beta)\right]\left[\gamma(2-b)^{2}(1+b)(2+b)-(1+\beta)[2-b(b+\beta)]\right]}>0 .
$$

The denominator is nothing but the product of the denominators of (14) and (26), hence it is positive, and the numerator is also positive.

\section{Proof of Proposition 4.}

Taking the difference between $c^{m}$ and $c^{n}$ yields

$$
c^{m}-c^{n}=\frac{(A-\alpha) \gamma(1+b)(1+\beta)\left[4 b-2 b^{2}-b^{3}-\beta\left(8-2 b^{2}+b^{3}\right)\right]}{\left[(2-b)^{2}(1+b)(2+b) \gamma-(1+\beta)[2-b(b+\beta)]\right]\left[4 \gamma(1+b)-(1+\beta)^{2}\right]} .
$$

The denominator of (45) is positive given that it is the product of the denominators of $c^{n}$ and $c^{m}$. The sign of the numerator hinges upon the sign of the last bracket. Setting this bracket equal to zero and solving for $\beta$ yields the critical value

$$
\beta^{c, p}(b)=\frac{4 b-2 b^{2}-b^{3}}{8-2 b^{2}+b^{3}}
$$

\section{Proof of Corollary 2.}

It follows from Proposition 3 and equations (17) and (29) that EG are higher under PC for any given values of $b$ and $\beta$. Comparing figures 4 and 9 (or, alternatively, comparing equations 19 and 46 , which is straightforward algebraically) reveals that $\beta^{c, y}>\beta^{c, p}$, which means that for $\beta \in\left(\beta^{c, p}, \beta^{c, y}\right)$, there are EG under PC, but not under QC.

\footnotetext{
${ }^{11}$ Available from the author upon request.
} 


\section{Computations for section 4.2}

First assume the three firms are independent. Solving the price stage yields the reaction functions

$$
p_{i}(\mathbf{x})=\frac{A\left(2+b-3 b^{2}\right)-\alpha(2+3 b)-(1+b)\left[(2+b+2 b \beta) x_{i}+(b+2 b \beta+2 \beta) \sum_{j \neq i} x_{j}\right]}{4+6 b}, \quad i=1,2,3 .
$$

Substituting these reaction functions into profit and maximizing w.r.t. R\&D yields

$$
x_{i}^{n}=\frac{(A-\alpha)(1+b)\left(2-b^{2}+3 b-2 b^{2} \beta-2 b \beta\right)}{4 \gamma\left(2-6 b^{2}+7 b\right)-(1+b)(1+2 \beta)\left(2-b^{2}+3 b-2 b^{2} \beta-2 b \beta\right)}, \quad i=1,2,3 .
$$

The $R \& D$ output given by this equation has the same properties as in duopoly (equation 26). Substituting (48) into the cost functions (1) yields equilibrium unit cost pre-merger, given by (31).

Now let firms 1 and 2 merge. Their profit is as in equation (22), and the profit of firm 3 is as in equation (23). Letting the merged firm choose $p_{1}$ and $p_{2}$, while firm 3 chooses $p_{3}$ yields the following reaction functions:

$$
\begin{gathered}
p_{i}(\mathbf{x})=\frac{2 A\left(2+b-3 b^{2}\right)-2 \alpha\left(2+6 b+2 b^{2}\right)-\left(4+4 b-b^{2}+2 b \beta+3 b^{2} \beta\right) x_{i}-\left(b^{2}+\beta\left(4+6 b+b^{2}\right)\right) x_{j}-2\left(b+b^{2}+2 \beta+2 b \beta\right) x_{3}}{8+8 b-4 b^{2}}, \\
p_{3}(\mathbf{x})=\frac{2 A\left(1-b^{2}\right)+2 \alpha(1+2 b)-2(1+b(1+\beta)) x_{3}-(b+2 \beta+3 b \beta)\left(x_{1}+x_{2}\right)}{4+4 b-2 b^{2}}
\end{gathered}
$$

Substituting (49) and (50) into the profit functions and letting the merged firm choose $x_{1}$ and $x_{2}$, and firm 3 choose $x_{3}$, and solving yields equilibrium R\&D outputs under merger. Again, as the solutions are quite cumbersome and not very informative, we elect to present the results graphically (figure 10). 


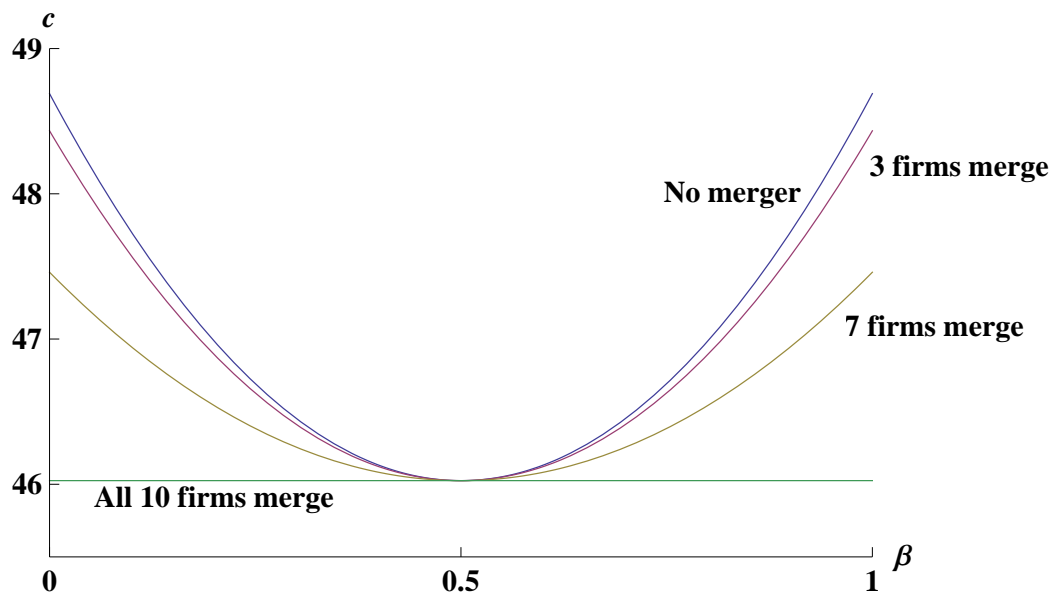

Figure 1. Unit costs in a 10-firm industry 


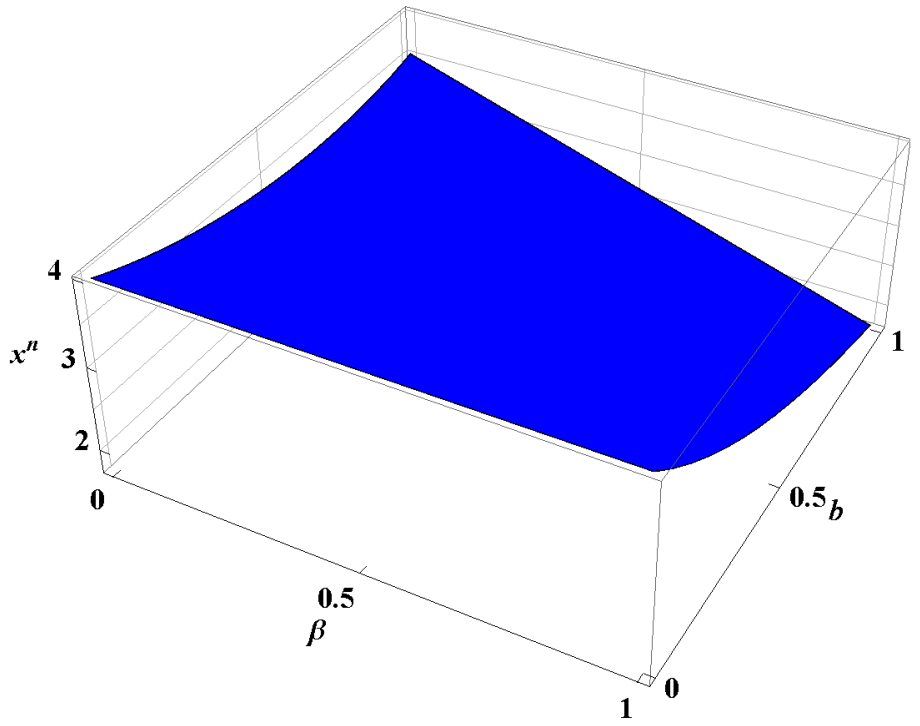

Figure 2. $R \& D$ in a duopoly with $Q C$ 


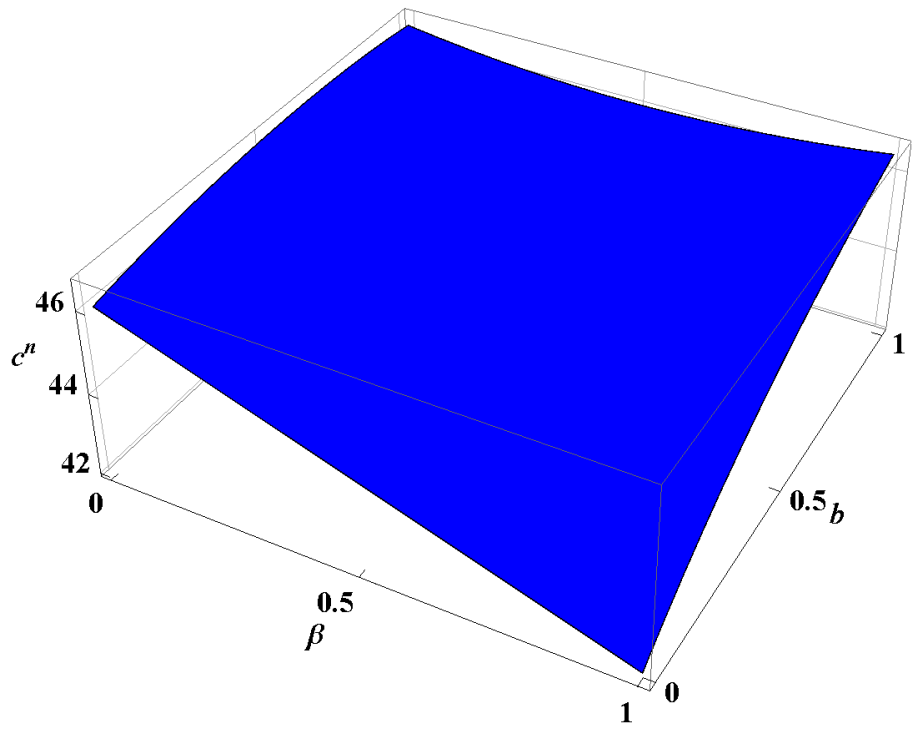

Figure 3. Unit cost in a duopoly with QC 


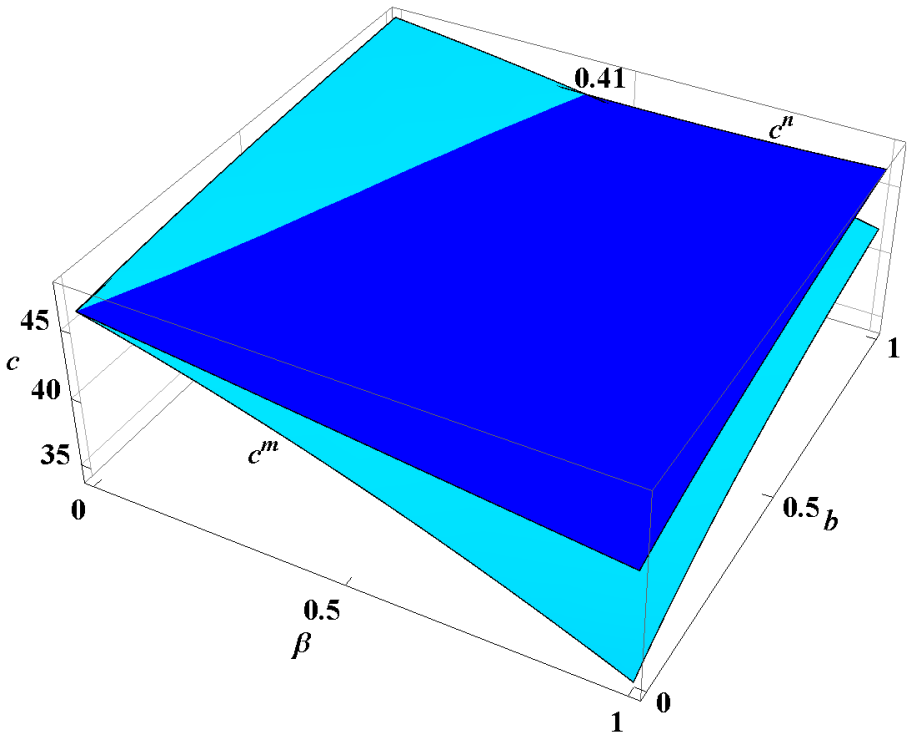

Figure 4. Unit costs with and without merger, $k=2$, QC 


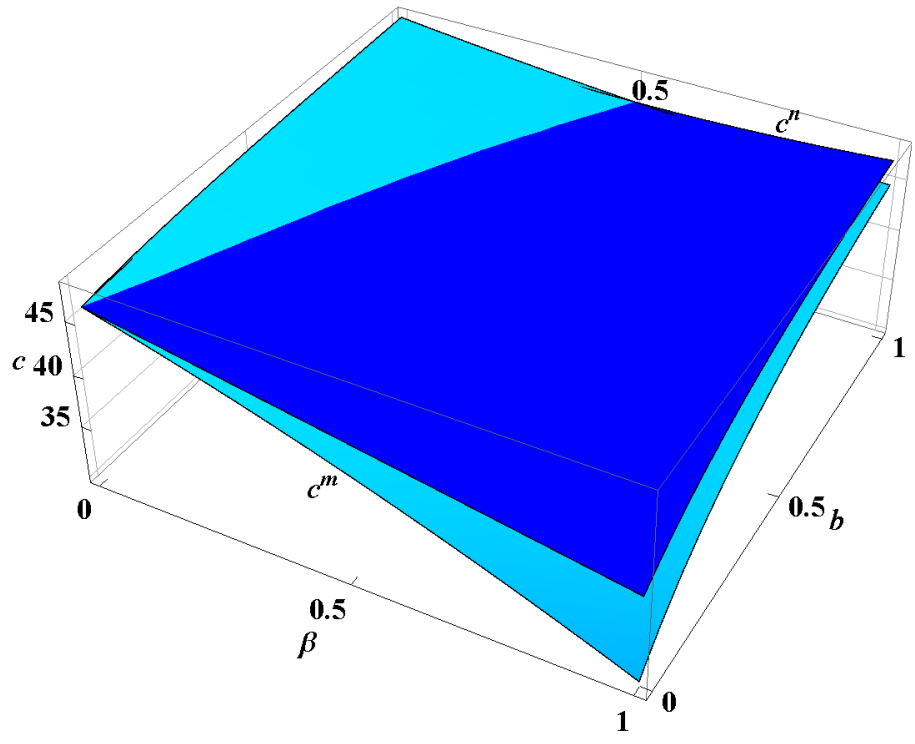

Figure 5. Unit costs with and without merger of two firms in a triopoly, QC 


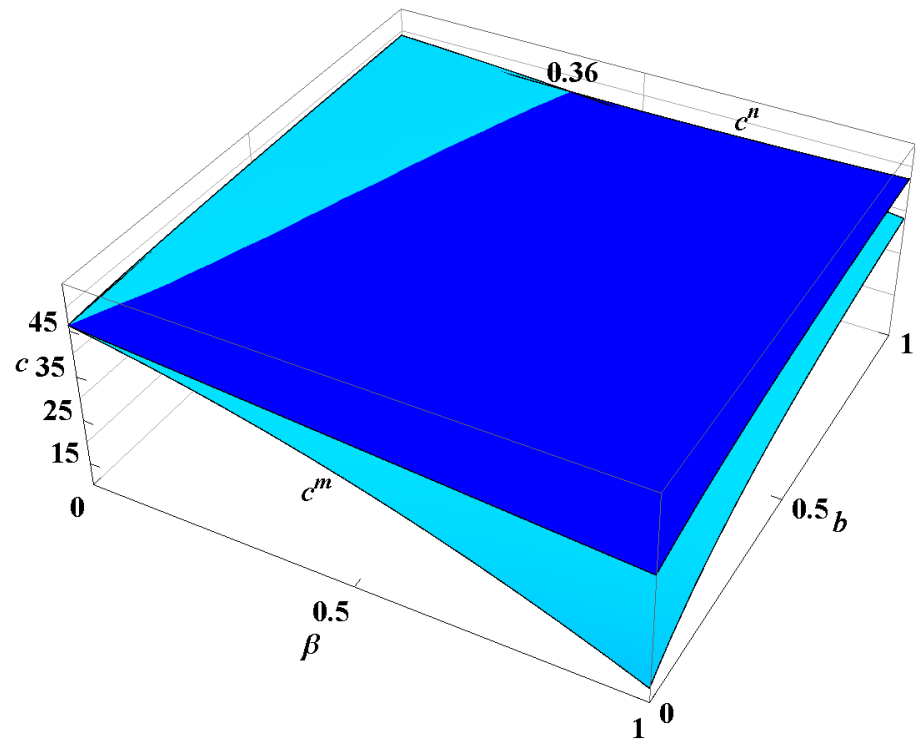

Figure 6. Unit costs with and without merger of three firms in a triopoly, QC 


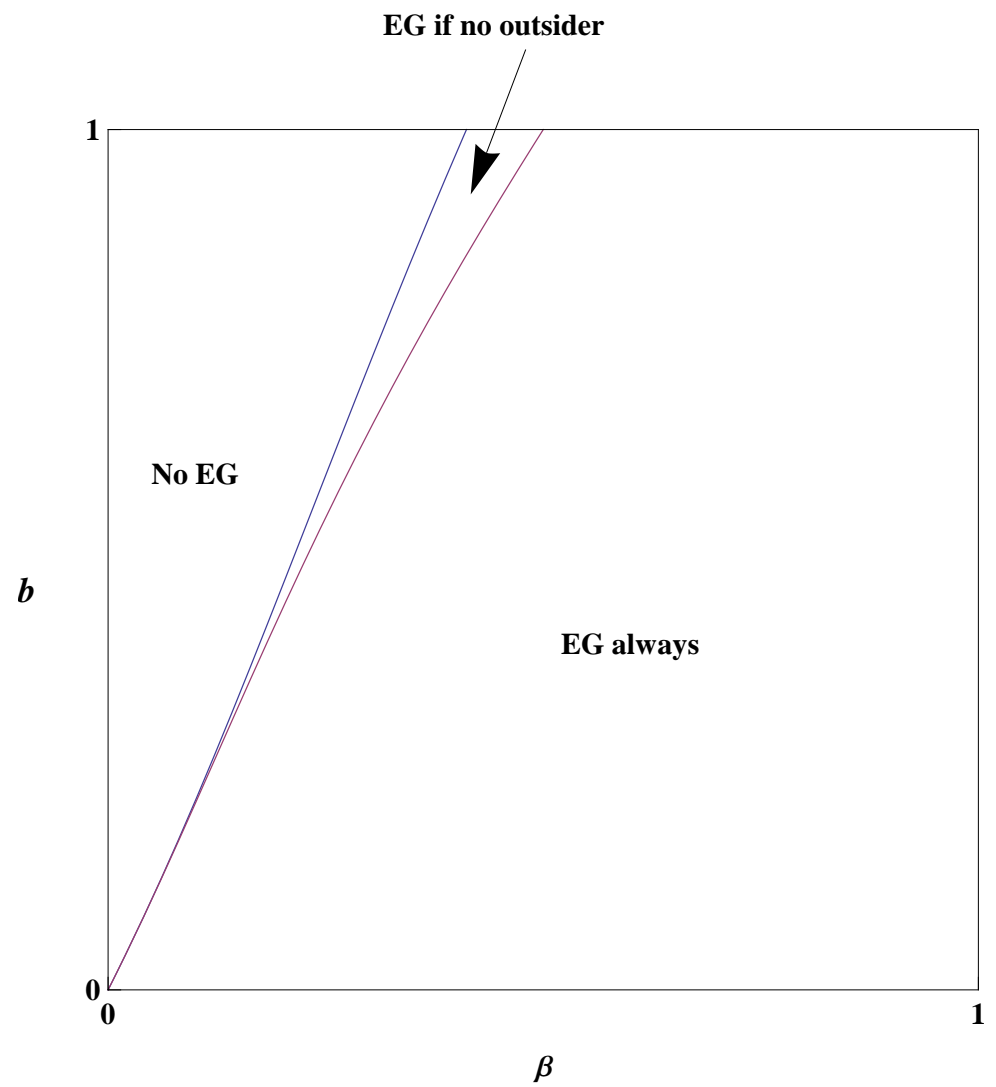

Figure 7. EG under QC with and without an outsider 


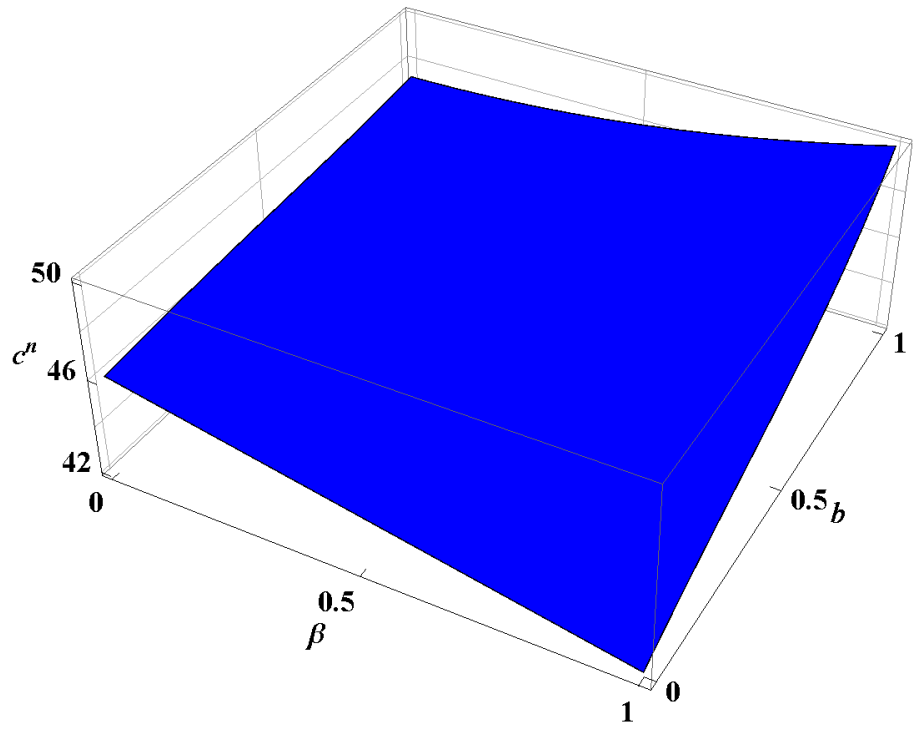

Figure 8. Unit costs in a duopoly with PC 


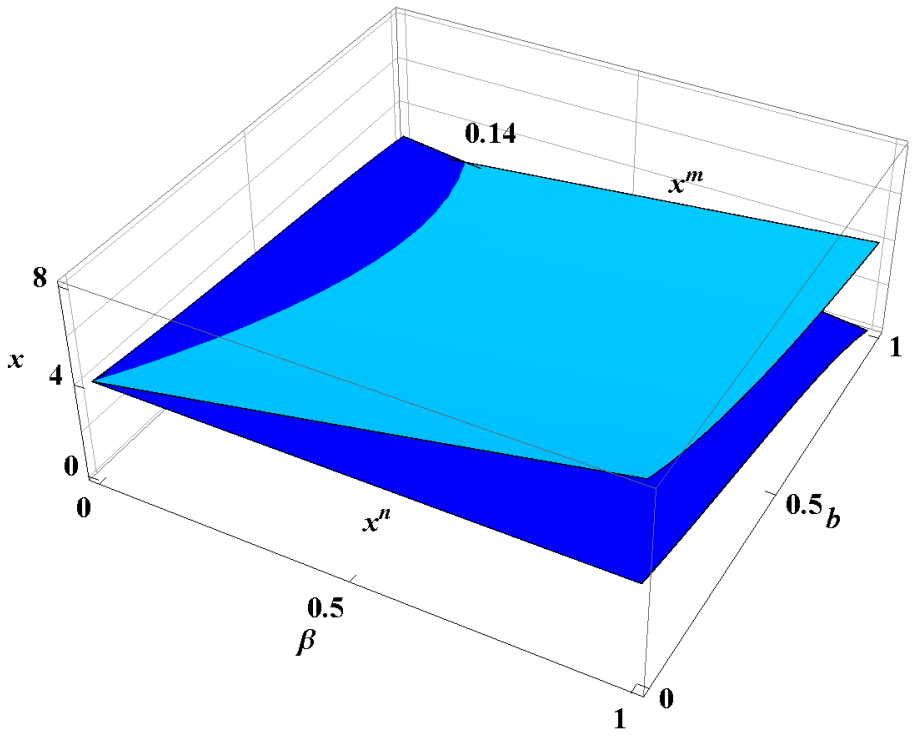

Figure 9. R\&D (per product) with and without merger in a duopoly, PC 


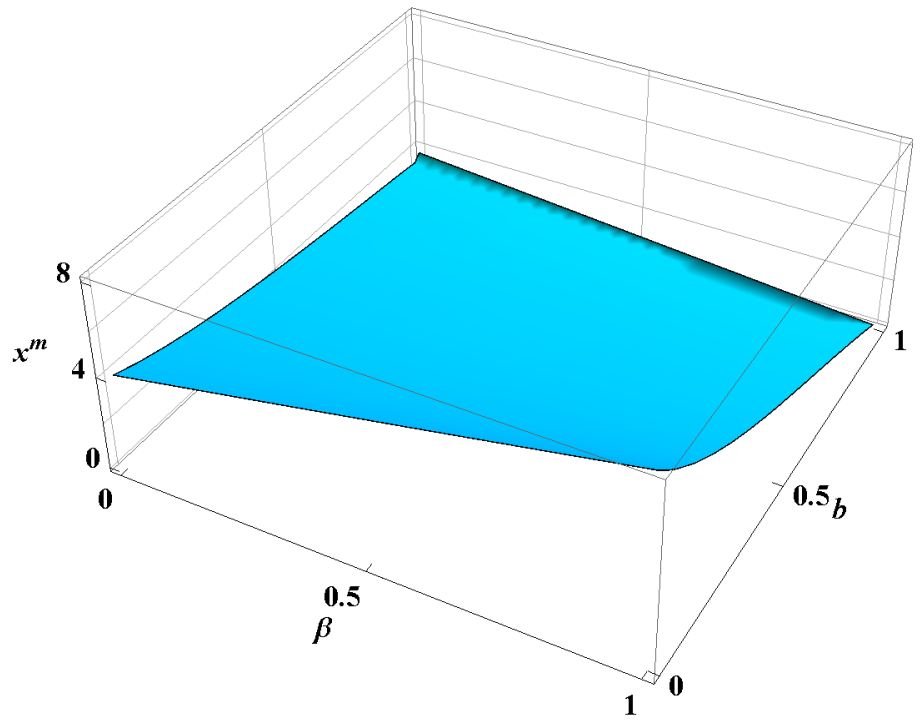

Figure 10. R\&D (per product) of the two merged firms in a triopoly, PC 


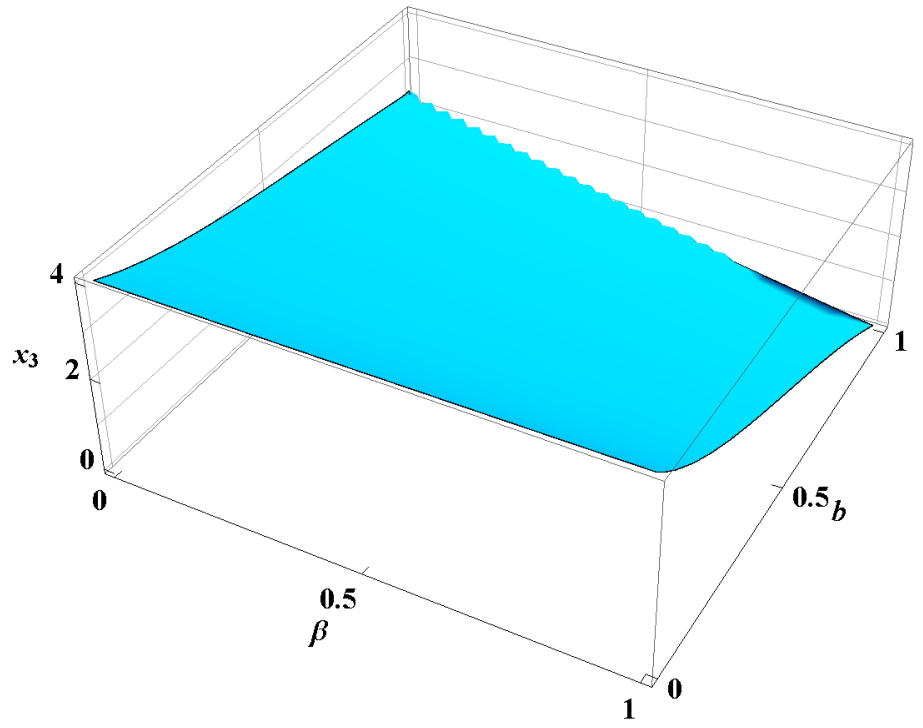

Figure 11. R\&D of the outsider when two firms merge in a triopoly, PC 


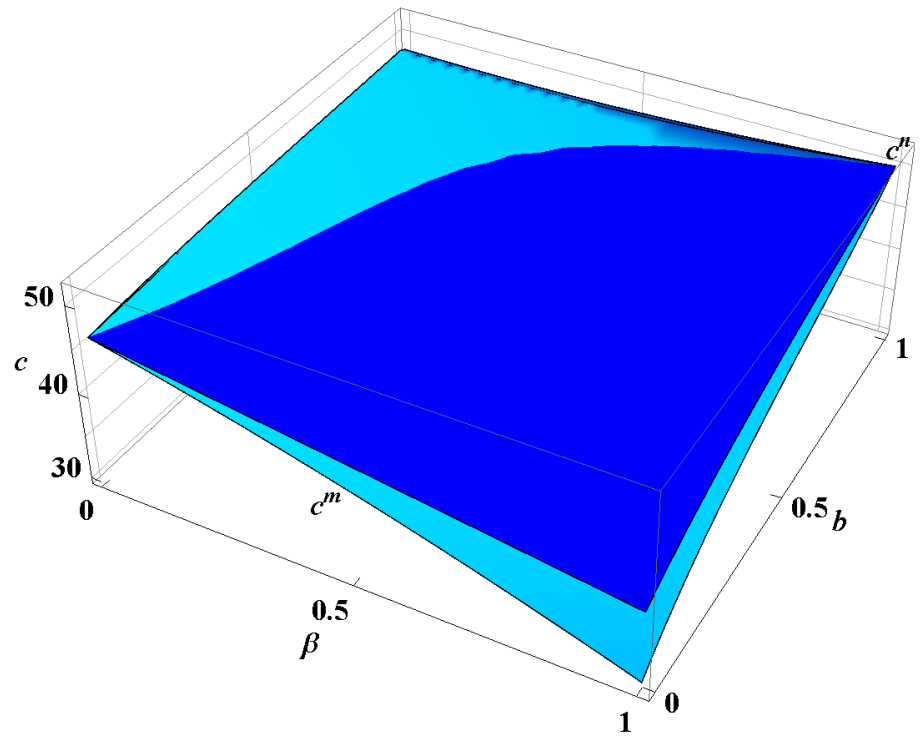

Figure 12. Unit costs with and without merger of two firms in a triopoly, PC 


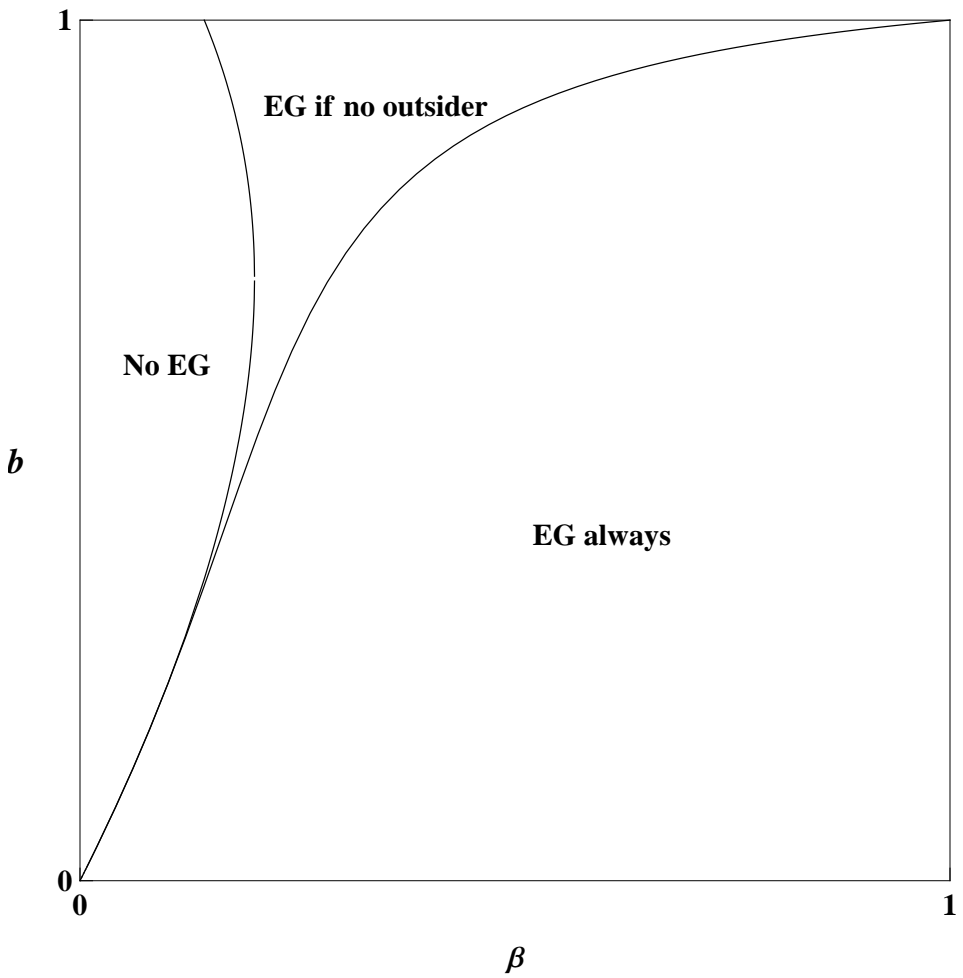

Figure 13. EG under PC with and without an outsider 


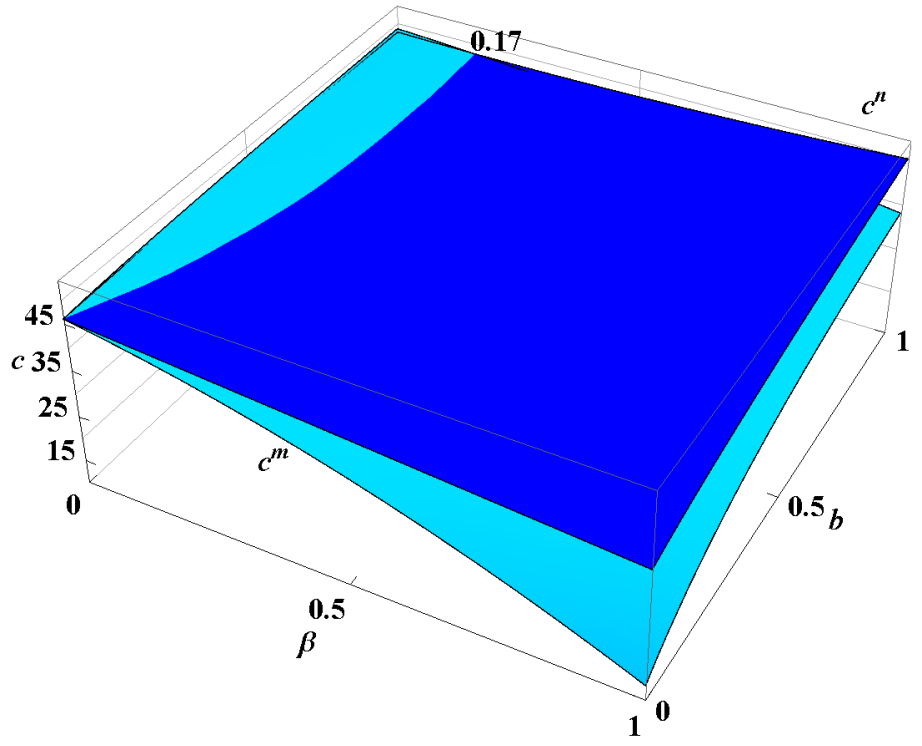

Figure 14. Unit costs with and without merger of three firms in a triopoly, PC 